\title{
Effect of steam addition on the flow field and NOx emissions for Jet-A in an aircraft combustor
}

\author{
Rui Xue \\ National Key Laboratory of Combustion, Flow and Thermo-Structure, Northwestern \\ Polytechnical University \\ 710072 Xi'an, People's Republic of China \\ ruixue87@126.com \\ Chunbo $\mathrm{Hu}^{1 *}$ \\ National Key Laboratory of Combustion, Flow and Thermo-Structure, Northwestern \\ Polytechnical University \\ 710072 Xi'an, People's Republic of China \\ huchunbo63@163.com \\ Theoklis Nikolaidis \\ Centre for Propulsion Engineering in the School of Aerospace, Transport and \\ Manufacturing, Cranfield University \\ MK43 OAL Bedfordshire, UK \\ t.nikolaidis@cranfield.ac.uk

\section{Pericle Pilidis} \\ Centre for Propulsion Engineering in the School of Aerospace, Transport and \\ Manufacturing, Cranfield University \\ MK43 OAL Bedfordshire, UK \\ p.pilidis@cranfield.ac.uk
}

\section{Abstract}

The steam injection technology for aircraft engines is gaining rising importance because of the strong limitations imposed by the legislation for NOx reduction in airports. In order to investigate the impact of steam addition on combustion and NOx emissions, an integrated performance-CFD-chemical reactor network (CRN) methodology was developed. The CFD results showed steam addition reduced the high temperature size

\footnotetext{
${ }^{1}$ Chunbo $\mathrm{Hu}$, Professor, Research direction is on gas turbine combustor and NOx emission.
} 
and the radical pool moved downstream. Then different post-processing techniques are employed and CRN is generated to predict NOx emissions. This network consists of 14 chemical reactor elements and the results were in close agreement with the ICAO databank. The established CRN model was then used for steam addition study and the results showed under air/steam mixture atmosphere, high steam content could push the NOx formation region to the post-flame zone and a large amount of the NOx emission could be reduced when the steam mass fraction is quite high.

Keywords: Chemical reactor network; Steam dilution; Aircraft engine; NOx emissions; CFD

$\operatorname{PACS}^{\circledR}(2010)$ (82.20.-w, 82.40.-g; 89.40.Dd; 82.33.Tb)

\section{Introduction}

Until the mid-1970s, steam addition into aircraft combustors has been studied ${ }^{[1-4]}$. As little benefit was readily seen while the drawbacks of servicing the system with steam were observed in old style steam injection systems, steam addition for aeronautical applications was not taken seriously. However, with an increasing concern about the effect of aircraft emissions on the local air quality at the vicinity of airports, steam or water injection method is becoming popular for aircraft engine NOx emission reduction at takeoff conditions.

Several studies have been undertaken to understand the influence of steam addition on fuel combustion and $\mathrm{NOx}$ emissions ${ }^{[5-14]}$. A preliminary aircraft performance investigation including system design, engine performance, maintenance, and cost implications of using water injection in aircrafts for takeoff operations was carried out at 
NASA Glenn Research Center ${ }^{[15,16]}$. As opposed to the old style water injection methods, it showed this approach could effectively reduce the Specific Fuel Consumption (SFC), NOx emissions, and turbine inlet temperatures as well. Furthermore, an experimental and numerical study conducted by Ernesto et al. ${ }^{[17]}$ showed that steam injection permitted a reduction of NO formation in a commercial turbojet chamber. However, most of them focus on simple gas fuels and the standard atmosphere is usually chosen as the operating conditions for both experimental and numerical studies. As little fundamental research has been performed on this topic, the effect of steam injection on kerosene combustion and NOx emissions at real gas turbine combustor conditions are not fully understood.

Concerning on NOx formation prediction, it is necessary to couple computational fluid dynamics (CFD) with a detailed set of chemical kinetics. Nevertheless, this requires great amounts of computation source and the solution of the whole equations is usually failed. Therefore, some methodologies which are partial coupling between CFD and chemical kinetics, have been developed and applied for NOx emission predictions. The unsteady flamelet model uses an unsteady marker probability equation to identify the scalar dissipation history in the converged flow field. Riesmeier et al. ${ }^{[18]}$ applied this method to a staged diffusion flame combustor and found that compared to steady flamelet results, the accuracy of the emission prediction could be improved. Pitsch et al. ${ }^{[19]}$ also calculated the NO concentrations in a reasonable agreement with experimental data for hydrogen/air diffusion flames by this approach. The post-processing NO formation model $^{[20]}$ transfers the basic emission mechanism into stored standard libraries and a PDF function is used to model the spatial fluctuations of temperature. Corresponding tests have been conducted by Gobbato et al. ${ }^{[21]}$ in gas turbine combustors. 
The use of CFD-based chemical reactor network (CRN) is not something new for NOx prediction simulation. Once the mean flow field is split into different zones, a number of perfectly stirred (PSR) and plug flow (PFR) reactors, both of which are widely used in kinetics analysis for flame are introduced to model the combustion process. Falcitelli et al. ${ }^{[22]}$ defined a general algorithm to construct a CRN. Mancini et al. ${ }^{[23]}$ adopted this method and found this methodology could accurately predict NOx emissions in several industrial cases. Park et al. ${ }^{[24]}$ applied CRN to an industrial lean-premixed gas turbine combustor and the prediction showed good agreement with experimental measurements. Fichet et al. ${ }^{[25]}$ proposed an optimized procedure to divide the reactive flow field into different zoned that could be modelled by PSR or PRF.

In modern gas turbine combustors, the inlet gas temperature is always larger than $800 \mathrm{~K}$ (water critical temperature is $647.5 \mathrm{~K}$ ). Thus, when water is injected in front of the combustor such as in the low pressure compressors, most of the inlet water would be in vapour phase at the combustor inlet. This, with no doubt, would lead the physical and chemical processes become more complicated in the combustor. Therefore, the influence of steam dilution on a generic aircraft combustor is investigated in this paper. Firstly, a brief review of the chemical kinetic effects of steam addition on hydrocarbon fuel combustion is provided thus the criterion for choosing a Jet-A chemical kinetics which is appropriate for this study could be confirmed. The effect of steam addition on the Jet-A flame temperature under real gas turbine conditions is studied. Secondly, in order to validate the turbulence and combustion models employed in this paper, the simulation for one experimental non-premixed turbulent flame jet is performed. Then the generic combustor geometry is presented and the CFD analysis is carried out under the steam 
content in the air/steam mixture from $0 \%$ to $15 \%$ by mass. Based on the converged flow field, a CRN is established. The CRN prediction of NOx emissions is compared with the experimental data and the results calculated by the other two NOx prediction models. Finally, the effects of steam addition on NOx reduction and its formation region are investigated.

\section{Modelling}

\subsection{D CFD RANS model}

Since even with modern supercomputers, resolving all turbulent length scales directly results in a tremendous effort. Therefore, for industrial application, the Reynoldsaveraged Navier-Stokes (RANS) methodology is frequently used to solve turbulent combustion flow fields. Coupled $k-\varepsilon$ model with the laminar flamelet model for gas turbine combustion research has been adopted by many researchers. O. Kunz ${ }^{[26]}$ compared the results calculated by a variety of different coupled turbulent models (Standard $k-\varepsilon, \mathrm{RNG}$ and RSM) and combustion models (EDC, Non-premixed equilibrium PDF, Laminar flamelet ) with the experimental data for one model combustor. It was showed that the laminar flamelet combustion model yields the best results. Furthermore, Cuoci et al. ${ }^{[27]}$ tested different turbulent models (Standard, RNG and Realizable $k-\varepsilon$ models) and found that the Standard $k-\varepsilon$ model gave the best results when the flamelet model was implemented. Therefore, in this paper, the standard $k-\varepsilon$ model with the laminar flamelet model is chosen as the turbulent model.

In the laminar flamelet model, the turbulent flame is represented by an ensemble of laminar steady-state stretched one-dimensional flames. The calculations of laminar flames are used to generate a flamelet library in which species mass fractions and the 
temperature are given in terms of the mixture fraction $Z$ and the scalar dissipation rate $\chi$. The mixture fraction $Z$ is an indicator of the mixture state between fuel and air, and could be built on the conservation equation of any element. The scalar dissipation rate is used to measure the strain in flame and quantify the state of non-equilibrium of the flamelet $^{18}$. It is defined as $\chi=2 D|Z|$, where $D$ is the scalar diffusivity which represents the local mixing rate. Therefore, from equations governing individual species transport and an overall energy balance, an individual laminar flamelet could be computed:

$$
\begin{aligned}
& \frac{1}{2} \rho \chi \frac{1}{L e_{i}} \frac{\partial^{2} w_{i}}{\partial Z^{2}}+\dot{\Omega}_{i}-\frac{1}{2} \frac{\delta w_{i}}{\delta Z}\left[\rho \chi \frac{1}{L e_{i}{ }^{2}} \frac{\delta L e_{i}}{\delta Z}-\frac{1}{2}\left(1-\frac{1}{L e_{i}}\right)\left(\frac{\delta \rho \chi}{\delta Z}+\rho \chi \frac{C_{p}}{\lambda} \frac{\delta}{\delta Z}\left(\frac{\lambda}{C_{p}}\right)\right)\right]=0 \\
& \frac{1}{2} \rho C_{p} \chi \frac{\partial^{2} T}{\partial Z^{2}}-\sum_{i=1}^{N s} H_{i} \dot{\Omega}_{i}-\rho \frac{\chi}{2} \frac{\delta T}{\delta Z}\left[\frac{\delta C_{p}}{\delta Z}+\sum_{i=1}^{N s} \frac{1}{L e_{i}} C_{p} \frac{\delta w_{i}}{\delta Z}\right]+\dot{Q}_{d}=0
\end{aligned}
$$

The last term in equation (2) quantifies the heat loss due to radiation from the diffusion flame. As the heat loss effects are particularly important on the NOx emissions, the $\mathrm{P}-1$ model $^{[28]}$, which assumes the radiation intensity is isotropic at a given location in the computation domain, is chosen. Then a probability density function (PDF) is employed to take account of the interaction between turbulence and chemistry.

Jet-A fuel is regarded as in liquid phase and the discrete phase model (DPM) is employed for combustor simulation, in which the spray is represented in the form of discrete particles using a Lagrangian formulation ${ }^{[29]}$. The primary breakup effect for fuel droplet is not addressed and only the secondary breakup is considered by using the Taylor analogy breakup (TAB) model ${ }^{[29]}$. Combined with the TAB model, the Discrete Random Walk model, which considers the turbulent dispersion effect on droplet movement, is implemented for stochastic tracking.

\subsection{CRN model}


Chemical reactor PSR includes a specific composition for species and temperature. In PSR, the continuity equations for each of the chemical species and the enthalpy equation are used to calculate the flux, which is also assumed in the steady-state in this study. The PFR models describe the steady-state tube flow reactor, in which it assumes that there is no mixing in the axial direction but perfect mixing in the directions transverse to this ${ }^{[30]}$. The governing equations for a plug-flow reactor are derived from the simplified version of the general relations for mass, momentum and energy. This reactor is adopted to represent the post flame zone on the combustor.

In this work, a CRN is designed for a turbofan combustor. As using steam addition during taxi phase would have little impact on NOx emission but increase CO formation, and the primary utility of steam addition is the reduction of NOx emissions around the airports, therefore, the effect of steam on NOx formation is investigated for takeoff condition.

\section{Effect of steam addition on kerosene chemical kinetics and NOx formation}

While steam addition is a well-known method for reducing flame temperature as its high heat capacity, it also provides NOx suppression benefits due to its oxygen displacement and participation effect in fuel reaction process. Several mechanisms of the chemical reactions with steam addition have been proposed. A brief description of these researches is presented below:

In hydrocarbon and hydrogen flames, steam affects the combustion reactions primarily due to its high chaperon efficiency in third-body reactions. Hwang, etc ${ }^{[12]}$ has conducted a numerical analysis to study the chemical effect of added $\mathrm{H}_{2} \mathrm{O}$ on flame 
structure and $\mathrm{NO}$ emission behaviour with detailed chemistry in the $\mathrm{CH}_{4}-\mathrm{O}_{2}-\mathrm{N}_{2}$ counter flow diffusion flames. Through chemical kinetics analysis, it showed $\mathrm{H}_{2} \mathrm{O}$ will restrain the chain branching reaction $\mathrm{H}+\mathrm{O}_{2}=\mathrm{O}+\mathrm{OH}$ by consuming $\mathrm{H}$ radical in the recombination reaction $\mathrm{H}+\mathrm{O}_{2}+\mathrm{M}=\mathrm{HO}_{2}+\mathrm{M}$. Thus, this could effectively be inhibited the methane combustion process. Furthermore, more $\mathrm{OH}$ radical was produced as both the reaction $\mathrm{OH}+\mathrm{H}_{2}=\mathrm{H}_{2} \mathrm{O}+\mathrm{H}$ and $\mathrm{O}+\mathrm{H}_{2} \mathrm{O}=2 \mathrm{OH}$ were enhanced when water is added. By experimental and numerical studies on the hydrogen/air flame structure with steam and other additives, Koroll and Mulpuru ${ }^{[8]}$ explained that the reason for the enhancement of the chain recombination reactions is the third-body efficiency of water reaches as high as 6.0. Other detailed measurement work carried out by Liu et al. ${ }^{[9]}$, Gurentsov et al. ${ }^{[11]}$ and Pellett, et al. ${ }^{[31]}$ also supported this mechanism. The experimental and computational investigations carried out by Mazas $^{[13]}$ showed that the concentration of $\mathrm{OH}$ radicals played a major role in fuel combustion when steam was injected. The kinetic modelling indicated the methane combustion was inhibited by steam addition because the reaction $\mathrm{H}_{2} \mathrm{O}+\mathrm{O}=2 \mathrm{OH}$ consumes more $\mathrm{O}$ radicals which is responsible for the methane oxidation through $\mathrm{CH}_{4}+\mathrm{O}=\mathrm{CH}_{3}+\mathrm{OH}$.

As steam affects the chemical mechanism significantly, the key elementary reactions illustrated above should be included during the Jet-A fuel flamelet library calculation. Several mechanisms have been developed for Jet-A fuel. For instance, Strelkova et al. ${ }^{[32]}$ designed a mechanism which is based on the surrogate fuel of $72.7 \mathrm{wt} \%$ decane, $9.1 \mathrm{wt} \%$ hexane, and $18.2 \mathrm{wt} \%$ benzene. Luche et al. ${ }^{[33]}$ also have developed mechanisms for common kerosene. Despite these mechanisms are capable of reproducing reasonable 
results and more computationally affordable, the main drawback is that they do not include some elementary reactions for steam addition or any NOx formation mechanism.

In this study, a mechanism provided by Kollrack ${ }^{[34,35]}$, which includes the essential elementary reactions with steam addition, is selected. In this mechanism Jet-A fuel is represented by the generic molecule $\mathrm{C}_{12} \mathrm{H}_{23}$. It contains of 24 species and 30 reactions. The first part of this mechanism consists of a two-stage pyrolysis, in which a radicalattack/cracking reaction involving $\mathrm{OH}$ is included. The second part is composed of the multiple elementary reactions for the simpler intermediate species combustion. The third and final part models the NOx chemistry, which includes the Zeldovich mechanism for $\mathrm{NO}$ formation and one global reaction for $\mathrm{NO}_{2}$ production. $\mathrm{NOx}$ production would be influenced as the variation of the radical pool induced by the mechanisms illustrated above. Therefore, the formation of NOx is primarily influenced by the flame temperature.

\section{Effect of steam addition on Jet-A fuel flame temperature}

Due to the complexity of kerosene compositions, to our knowledge, in public domain, few investigations are carried out on Jet-A flame with steam dilution in real gas turbine combustor conditions. Therefore, the adiabatic flame temperature, which is one of the most important parameters during the flamelet library establishment, is investigated first. Furthermore, in order to verify the accuracy of the Kollrack mechanism, the calculated data are also compared with the results calculated by the standard NASA's Chemical Equilibrium Analysis software (NASA-CEA) ${ }^{[36]}$ with steam addition. 


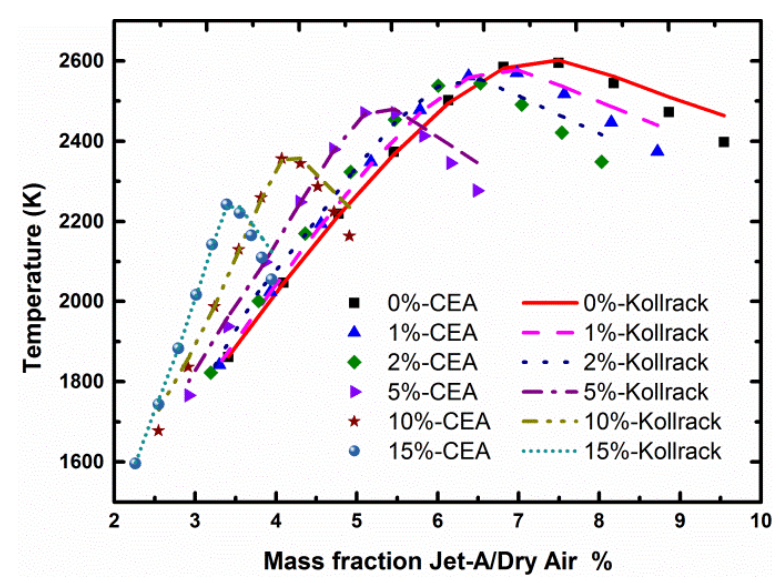

Figure. 1 Adiabatic flame temperature of Jet-A at takeoff condition for different steam levels

The results are shown in Figure.1 at different steam mass fractions. The steam mass fraction here means the ratio of steam mass flow rate to the total steam/air mixture mass flow rate and the operating pressure is obtained from the engine performance simulation. Generally, it could be seen that the prediction of Kollrack mechanism is in good agreements with CEA results. The maximum of the adiabatic flame temperature decreases from $2600 \mathrm{~K}$ at dry air condition to $2250 \mathrm{~K}$ as the steam mass fraction reaches to $15 \%$ in the air-steam mixture. The Kollrack mechanism tends to overestimate the flame temperature in fuel rich conditions at any steam mass fraction. The reason is the global reaction model that is used to describe the Jet-A pyrolysis process does not consider detailed fuel rich reaction compositions in this process.

Furthermore, taking the dry condition as reference (the solid red line), it could be seen that when fuel is rich (Jet-A/dry air(in mass) >0.06817), adding steam would lead the flame temperature decrease. At fuel lean conditions (Jet-A/dry air <0.06817), however, it has an intersection point with any other lines that represents the condition with steam addition. These points represent the limit of the steam mass fraction at which its chemical heat enhancement effect could counteract its thermo-physical heat inhibition 
influence. For the value of Jet-A/dry air ratio at the intersection point, the heat loss caused by the effects of thermo-physics with steam addition could be compensated by the heat addition induced by its chemical influence. Therefore, the flame temperature will not be altered if this amount of steam was injected. However, when the steam mass fraction exceeds this intersection point, the thermo-physical inhibition effects become the primary part and subsequently, the flame temperature will decrease.

\section{Validation of the CFD model}

In order to validate the applicability of the coupled turbulent and combustion models in this study, the numerical calculation for the DLR-A flame is carried out. This flame is part of the International Workshop on Measurement and Computation of Turbulent Nonpremixed Flames (TNF), and extensive measurement data is included ${ }^{[37]}$. Once the flame is calibrated, this CFD models could then be applied for the combustor computation. The main operating and boundary conditions of this jet flame are: Fuel gas: $\mathrm{CH}_{4}(22.1 \%): \mathrm{H}_{2}(33.2 \%): \mathrm{N}_{2}(44.7 \%)$ by volume. Fuel velocity: $43 \mathrm{~m} / \mathrm{s}(\mathrm{Re}=15200) . \mathrm{Co}-$ flow velocity: $0.3 \mathrm{~m} / \mathrm{s}$. Fuel nozzle diameter: $8 \mathrm{~mm}$. Co-flow nozzle diameter: $140 \mathrm{~mm}$. The jet is a fully developed pipe flow thus the $1 / 7$ th power law is assumed as its velocity distribution. Pressure operation was taken as $1 \mathrm{~atm}$. A recently updated 17 species and 49 reactions chemical mechanism based on the work of Nikolaou and his co-workers ${ }^{[38]}$ is used to carry out the flamelet library computation. A second-order upwind scheme is used for all equations. The coupling between velocity and pressure is accomplished based on SIMPLE algorithm. 

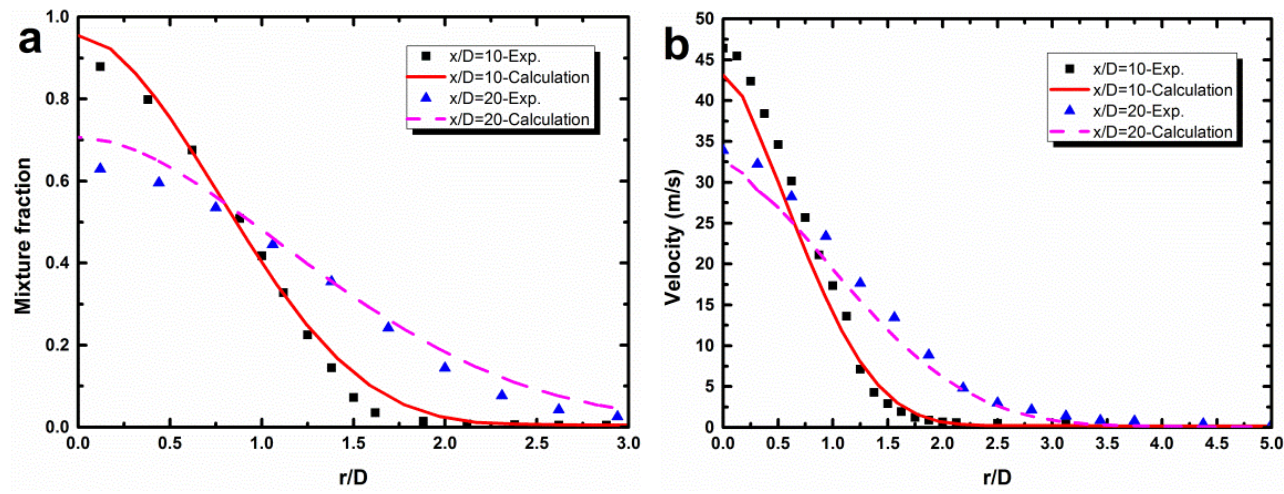

Figure. 2 Mean values of a) mixture fraction and b) axial velocity profiles in $\mathrm{r}$ direction at $\mathrm{x} / \mathrm{D}=10$ and 20

For the combustion flow field simulation, attention should be directed towards the velocity and mixing scalar distribution of the reactive flow field. The velocity distribution represents the performance of the turbulent model and the mixture fraction is an independent value that is used to obtain other combustion scalars. Therefore, Figure.2 shows the comparison between the calculations and the measurements for radial distributions of the mixture fraction and the mean velocity at two section areas located at $\mathrm{x} / \mathrm{D}=10$ and 20 downstream, where $\mathrm{x}$ is the axial position and $\mathrm{D}$ represents the burner diameter of the flame. The calculation results have the same trend as measurements: both the velocity and the mixture fraction decrease from the centerline to co-flow sides and the mixing gases tend to be more uniform at downstream.

Then the axial distributions of these two parameters in the centerline are shown in Figure.3. From the axial location of $\mathrm{x} / \mathrm{D}=10$, the underestimation of temperature and mixture fraction is observed. This is caused by the underestimation of the mixing at the centerline which could be also spotted in Figure.2. 


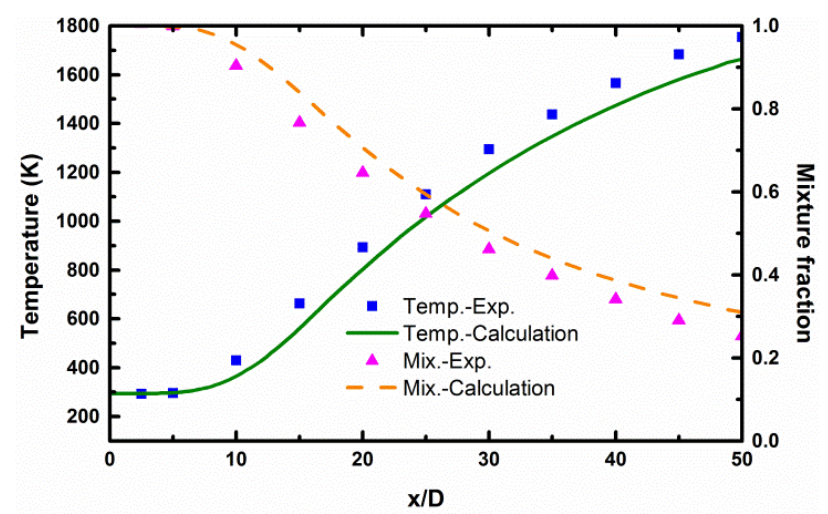

Figure. 3 Mean values of temperature and mixture fraction profiles in $\mathrm{x}$ direction at centreline

The detailed flow field analysis is not illustrated here and the reader could refer [37] for more details. Based on these results, it could be concluded that the CFD method in this investigation is in quantitatively good agreement with experiment and could be adopted for the combustor simulation in the next section.

\section{Application for gas turbine combustors}

\subsection{Gas turbine engine performance simulation}

As the real operating conditions for the engine components are confidential and could not be got from public domain, therefore, in order to obtain the boundary conditions for the combustor simulation, a generic, two-shaft, high bypass ratio gas turbine engine model, similar to the Rolls-Royce AE3007-A2 series engines ${ }^{[39]}$, was established under the environment of the in-house software Turbomatch. The model is based on component characteristics, which makes this modular code is able to simulate a new cycle without creating a new source program. Compressor inlet and turbine outlet pressure losses are accounted for in this model. For complete description of the related theory and the computation process in this code, the reader is referred to [40] and [41]. 
In this model, the takeoff condition was chosen as the design point (DP) because more information in this condition was available in public domain. The off design points were taken at three other landing and takeoff cycle (LTO). According to the Federal Aviation Administration (FAA) requirement, it breaks down the LTO into four modes ${ }^{[42]}$ : 1) Takeoff: full-throttling operation (100\% power setting); 2) Climb-out: the period during the aircraft leave the mixing zone (85\% power setting); 3) Approach: the period during the aircraft enter the mixing zone when it lands (30\% power setting); 4) Idle: the period during the aircraft is taxiing before takeoff and after landing (7\% power setting).

By matching the takeoff rated thrust, the simulation was performed and the results are shown in Table 1. It shows that a good agreement was established between the results and the expected engine output reported by ICAO Engine Emissions Databank ${ }^{[42]}$. The resulted conditions of inlet air total temperature $T_{3}$ and pressure $P_{3}$, and both the fuel and the air flow rates at the compressor outlet is then provided for the CFD combustion simulation.

Table 1 Comparison of computed cycle data (by TurboMatch) and published data ${ }^{[40]}$

\begin{tabular}{|c|c|c|c|c|c|c|}
\hline \multicolumn{2}{|c|}{ Engine parameters } & Simulation & \multicolumn{2}{|c|}{ ICAO data bank } & \multicolumn{2}{|c|}{ Deviation } \\
\hline \multicolumn{7}{|c|}{ DP (Takeoff) } \\
\hline \multirow{2}{*}{\multicolumn{2}{|c|}{$\begin{array}{l}\text { Thrust }(\mathrm{kN}) \\
\text { SFC }(\mathrm{mg} / \mathrm{Ns})\end{array}$}} & 43.06 & \multicolumn{2}{|c|}{42.23} & \multicolumn{2}{|r|}{$1.9 \%$} \\
\hline & & 10.85 & \multicolumn{2}{|c|}{9.35} & \multicolumn{2}{|r|}{$16.0 \%$} \\
\hline & Flow $(\mathrm{kg} / \mathrm{s})$ & ICAO data bank $(\mathrm{kg} / \mathrm{s})$ & Deviation & $\mathrm{P}_{3}(\mathrm{~atm})$ & $\mathrm{T}_{3}(\mathrm{~K})$ & Air flow rate $(\mathrm{kg} / \mathrm{s})$ \\
\hline Takeoff & 0.4683 & 0.466 & $0.49 \%$ & 20.0 & 725.5 & 19.6 \\
\hline Climbout & 0.3745 & 0.388 & $-3.4 \%$ & 17.4 & 691.2 & 17.7 \\
\hline Approach & 0.1207 & 0.138 & $-12.5 \%$ & 8.4 & 550.6 & 9.8 \\
\hline Idle & 0.0544 & 0.055 & $-1.1 \%$ & 4.3 & 469.2 & 5.0 \\
\hline
\end{tabular}

\subsection{Generic annular combustor and boundary conditions}

A model annular-type gas turbine combustor is used to carry out the flow field investigation. The length of the combustor is of $225 \mathrm{~mm}$ and the maximum radius of $364 \mathrm{~mm}$. The combustor liner is composed of 22 swirl cups equally spaced along the 
circumferential direction. Due to the inherent geometric symmetry of the chamber, only one sector will be modelled to reduce the size of the problem. Within a single-cup sector, there are 4 dilution ports on both the external and internal liners, and 11 cooling rings are distributed for the whole flame tube. The detailed geometry of cooling rings is not represented because they are composed of a huge number of small holes while the number of cells in the grid is limited. Therefore, the cooling rings are simply represented as continuous features. The fuel injector is modelled by three concentric circular inlets disposed on the base-plate. The first and third ones represent the swirler air exits and the middle one corresponds to the fuel injector. An overview of the burner geometry is shown in Figure.4.

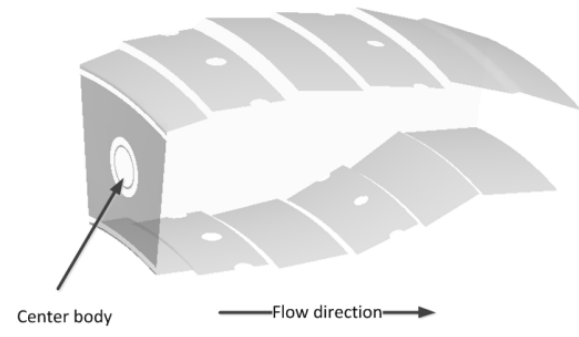

Figure. 4 Single-cup sector of the combustor chamber

Specifically, the treatment of the fuel injector inlet velocities at the dome of the combustor should be appropriately managed. Generally, in order to produce a recirculation region in the primary zone, the swirler number should be larger than 0.6 . In the present work, based on the design swirler number, a velocity profile for the radial, tangential and axial velocity components at different points in the inner and outer swirler exits are derived from a previous CFD simulation of one generic swirler and scaled to this simulation. The distribution of the mass flows shown in Table 2 was calculated using 
the combustor design model. The velocity inlet is used as boundary conditions. The jet penetration angles were also computed by the combustor design model. Film cooling is not correctly modelled since the development of the boundary layer in the cooling film is strongly linked with the jet velocity. The direction of film cooling jets is assumed parallel to the wall except the last one on the internal casing.

Table.2 Mass fraction for different air inlets at take-off condition

\begin{tabular}{llc}
\hline & Feature & Mass flow (\%) \\
\hline Baseplate & Internal swirler & 9.14 \\
& External swirler & 18.5 \\
& Cooling ring & 2.8 \\
Outer & Cooling ring & 3.82 \\
liner & Cooling ring & 4.97 \\
& Dilution port & 8.89 \\
& Cooling ring & 4.76 \\
& Cooling ring & 5.41 \\
& Dilution port & 7.24 \\
Inner & Cooling ring & 5.01 \\
liner & Cooling ring & 3.55 \\
& Dilution port & 8.98 \\
& Cooling ring & 3.52 \\
& Cooling ring & 3.41 \\
& Dilution port & 5.72 \\
& Cooling ring & 3.50 \\
& Cooling ring & 0.78 \\
\hline
\end{tabular}

All solid surfaces are assumed as $1 \mathrm{~mm}$ thick steel-made walls. Convection and radiation heat transfers are taken into account to calculate the heat loss from the boundaries. To simulate the external heat transfer by convection, an external heat transfer coefficient has been estimated from data available. The value found is $600 \mathrm{~W} /\left(\mathrm{m}^{2}{ }^{\circ} \mathrm{C}\right)$. The main problem here is that the value is constant along the wall. Therefore, the heat exchange is overestimated in some areas and underestimated in others.

Turbulence intensity for the inlets is taken to be $10 \%$ and the length scale is $5 \mathrm{~mm}$. These assumptions have little effect on the final solution because the amount of turbulence generated in the combustor is far greater. P1 model is employed to calculate the radiative heat transfer. The only parameter to fix is the emissivity factor. A value of 
0.6 is taken for all the inlets and the outlet. A value of 0.8 is used for the wall emissivity, thus the radiation with external medium can be taken into account. The emissivity of the internal wall is higher due to deposits of soot. Therefore, a value of 0.85 has been chosen. The weight-sum-of-gray-gases model (WSGGM) is used for computation of a variable absorption coefficient.

For droplet size distribution, the function developed by Rosin and Rammler ${ }^{[43]}$ is used with the $40 \mu \mathrm{m}$ Sauter-Mean-Diameter (SMD). The magnitude of droplet size spread parameter is set as 2.5 proposed by Lefebvre ${ }^{[44]}$. Furthermore, in order to take the droplet evaporation heat loss into account during the flamelet library calculation, the gas fuel inlet temperature is set based on the following equation:

$$
T_{\text {fuel }, g}=T_{\text {fuel, },}-L_{\text {vap }} / C_{p c}
$$

where $T_{\text {fuel,g }}$ represents the gas fuel inlet temperature for flamelet calculation, $T_{f u e l, l}$ is the inject liquid fuel temperature, $L_{v a p}$ is the latent heat of evaporation and $C_{p c}$ is the droplet specific heat. For Jet-A fuel, if the inject droplet temperature is $298.15 \mathrm{~K}$, the gas fuel inlet temperature is $180.01 \mathrm{~K}$.

To study the grid dependence of the solution, three different grid sizes: 60,000, 124,000 and 275,000 cells, which represent coarse, medium and fine grids respectively, were tested. The numerical results were obtained and found that the medium size grid is accurate enough to get the basic flow fields. More cells are added in the central zone to get a good representation of the mixing between air and Jet-A.

\subsection{Combustor reactive flow field}

The simulation of the reactive flow field is conducted over different operating settings from takeoff to idle conditions. As the steam is assumed to be injected in front of 
the combustor, the steam content is the same for any air inlets or cooling slots in the burner. The operating conditions used in this simulation are shown in Table 1.

The aim of this study is to investigate the effect of steam composition on the combustor flow field and NOx emissions. Therefore, in order to exclude other factors, the operating conditions like the combustor inlet pressure $\mathrm{P}_{3}$, temperature $T_{3}$, the total fuel flow rate and the total flow rate the steam/air mixture are all kept the same as that in the dry air condition. Only the inlet steam mass fraction is varied from $0 \%$ to $15 \%$ by mass in the air/steam mixture.

Table.3 Comparison of the combustor outlet temperatures calculated by CFD and Turbomath

\begin{tabular}{cccc}
\hline \multicolumn{4}{c}{ Combustor outlet temperature } \\
\hline Power & CFD outlet mass-weight & Turbomatch turbine inlet & Difference \\
setting & average temperature(K) & temperature (K) & \\
Takeoff & 1511.151 & 1520 & $-0.58 \%$ \\
Climbout & 1399.455 & 1408 & $-0.607 \%$ \\
Approach & 1010.531 & 1003.95 & $0.656 \%$ \\
Idle & 893.9099 & 881.97 & $1.35 \%$ \\
\hline
\end{tabular}

The calculation reaches on the convergence when the residuals for all the controlling equations are less than $10^{-6}$ and the variation of the burner outlet temperature and the species concentration is less than $1 \%$. In order to further verify the accuracy of this CFD model, the comparison of the combustor outlet temperatures calculated by CFD and Turbomatch at different power setting conditions is shown in Table 3.

Figure.5 (a) shows contour plots of the mean total temperature for both dry and high wet cases $(15 \%)$ on the immediate plane of the combustor. As can be seen, the V-shape of flame, which is the primary characteristics for swirl spray combustion, is captured reasonably. The combustion occurs in the shear layers induced by the fuel jet with both the inner and outer swirler air jets in the primary zone. This is the reason why the flame is in $\mathrm{V}$-shape. The penetration of the dilution jets in the primary zone is clear and creates a stagnation area, which is benefit for maintaining the flame and forcing the combustive 
radicals to go around it. In addition, the flame expands to the central high mixing scalar region at the secondary zone. One reason for this is that the Jet-A fuel employed in this calculation is in liquid phase. Therefore, the fuel droplet must evaporate first before the combustive fuel vapour/air forming. This would lead the whole fuel vapour diffusion and mixing process to be postponed.
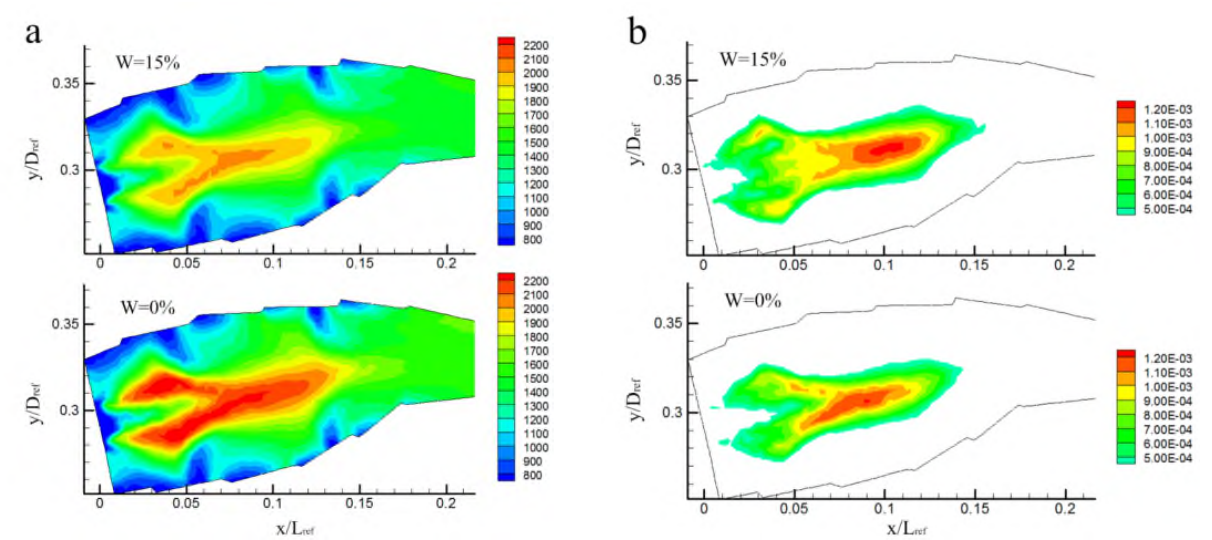

Figure. 5 Contours of the a) Total temperature and b) $\mathrm{OH}$ radical distribution in the immediate plane of the combustor at takeoff condition for the dry $(\mathrm{W}=0 \%)$ and wet cases $(\mathrm{W}=15 \%)\left(\mathrm{T}_{\text {air }}\right.$ or $\mathrm{T}_{\text {air/steam }}=725.54 \mathrm{~K}$, Jet-A droplet=298.15K)

From the temperature contour, it could be seen when steam is injected, the size of the flame zone would be reduced. In addition, Figure.5 (b) illustrates the distribution of $\mathrm{OH}$ radical mass fractions for these two cases. In order to get better comparison, the regions for which the $\mathrm{OH}$ mass fraction is below $0.04 \%$ are not displayed here. It shows that steam tends to extend the radical pool size and pushes the flame front downstream from the fuel injectors. Based on the analysis above, among the three mechanisms when steam is added, both the thermal and the reactant dilution effects play a primary role for the whole combustion performance. These two mechanisms lead the combustion temperature decrease even with higher $\mathrm{OH}$ radical concentration in the flame core with 
steam addition. It is noted that though no experiments have been obtained to further confirm this conclusion, the experimental study of the natural gas and hydrogen mixture combustion with steam addition conducted by Göke et al. ${ }^{[14]}$ also comes to the similar conclusions. By using PLIF for measuring Abel deconvoluted $\mathrm{OH}^{*}$ chemiluminescence, they found that at wet conditions, the flame speed is reduced and the reaction rates are lower, which leads to a wider reaction zone and moves the maximum of the $\mathrm{OH}^{*}$ radiation concentration further downstream and closer to the combustor walls ${ }^{[14]}$.
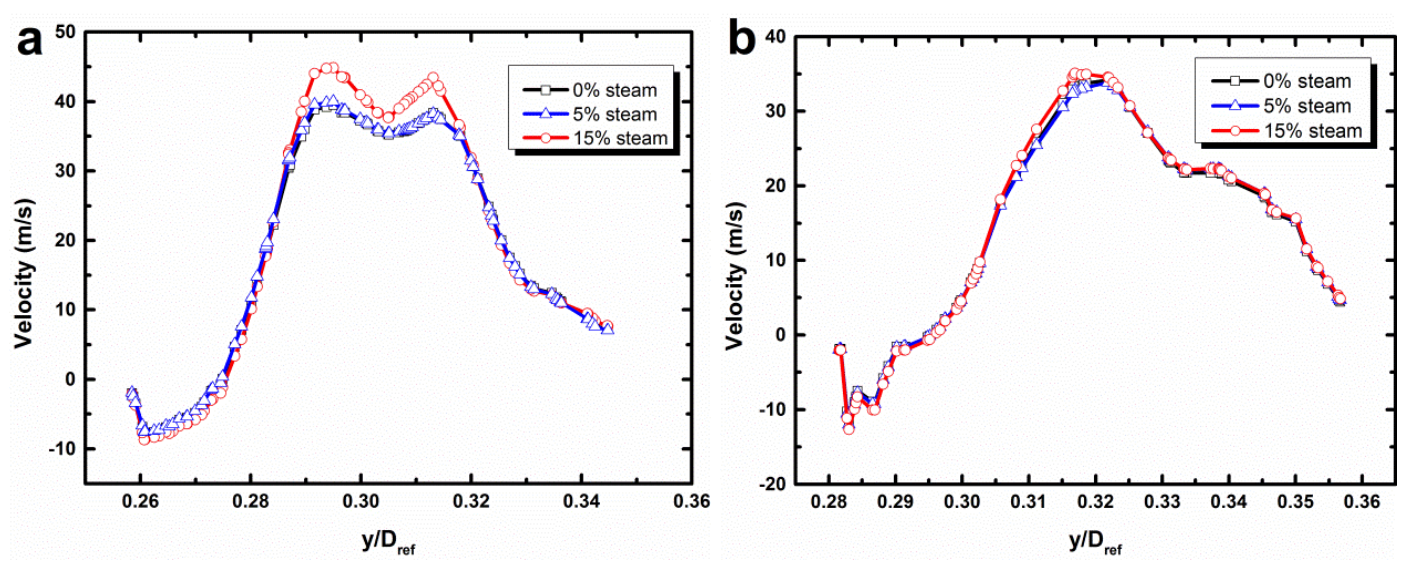

Figure. 6. Radial distribution of axial velocity at a) the primary jet and b) the secondary jet cross sections

It could be seen that the whole flow field topology is similar and does not change significantly with steam addition. The flow filed could be further illustrated in Figure.6 for the radial velocity distributions at the primary and secondary jet cross sections respectively. It is obvious that when the injected steam mass fraction is low (5\%), the velocity distributions at both the primary and secondary jet cross sections are not altered significantly. However, when the mass fraction of the added steam reaches $15 \%$, the gas velocity in the core flow at the primary jet area which is within the hottest zone is increased while the flow is nearly not affected at the secondary jet area. This is in 
accordance with the temperature distribution shown in Figure.5. Therefore, the steam addition primarily influences the flame zone in the combustor.

\subsection{CRN Establishment}

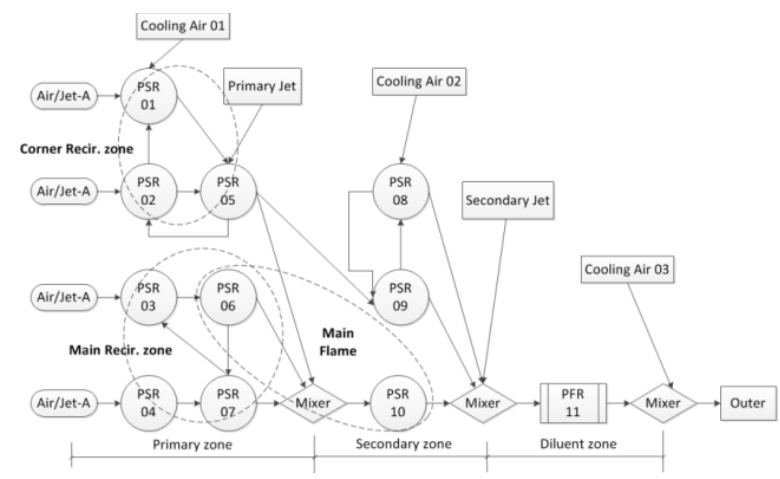

Figure. 7. A 14-element CRN used to calculate the NOx emission of this generic combustor model

The combustor CRN is established based on the converged flow filed calculated above. As shown in Figure.5, the combustor can be divided into different reactor zones. The flame zone is confirmed by both the temperature and the radical distributions. Recirculation zones at the dome corner, the main core and the jet upstream are determined by the velocity and the temperature distributions. In addition, the dilution zone is approximately represented by the one-dimensional flow reactor, PFR. Many other PSR reactors are included to represent the cooling flows at the near-wall regions. Furthermore, due to Jet-A is in liquid phase, it atomizes and evaporates after ejecting from the injector exit. This process occurs at the premixed regions between the flame and the dome. Therefore, multiple PSRs with different equivalence ratios are used to represent this region. The equivalence ratios at different PSRs are determined based on the Jet-A evaporation model.

The network architecture is shown in Figure.7. 4 PSRs at the premixed zone with different equivalence ratios are applied. After the primary zone, the secondary zone 
consists of 3 PSRs in parallel to model the core flame zone, the intermediate diffusion zone and the near-wall zone respectively. Then the exhaust of the secondary zone will be mixed with the secondary jet and this mixture is sent to the dilution zone represented by a PFR. Though the flame and flow patterns are varied a lot among different conditions calculated by CFD, these distinct zones described above are maintained. Thus, the structure of this CRN model will be kept the same while the mass exchanges and the volume for different reactors were recalculated based on the flow field at each specific condition.

\subsection{Comparison of the CRN prediction with the experimental data and other NOx prediction models}

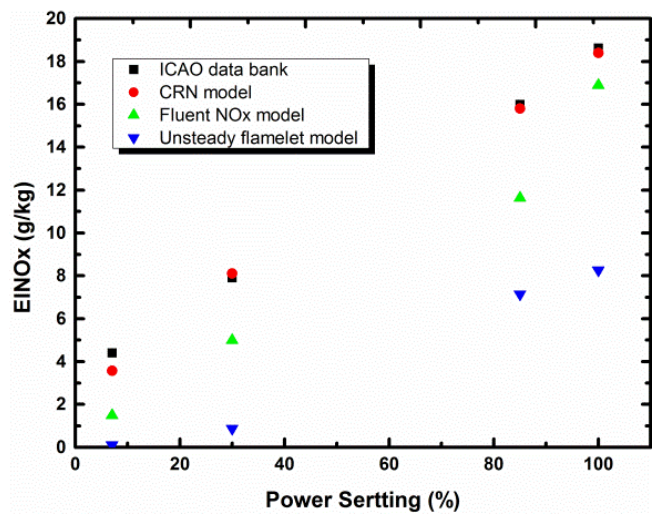

Figure. 8 Comparison of EINOx prediction with test data at different power setting conditions

Figure. 8 shows the NOx emission indices $(E I N O x=N O x$ mass flow rate $(\mathrm{g} / \mathrm{s}) / \mathrm{fuel}$ mass flow rate $(\mathrm{kg} / \mathrm{s})$ ) calculated by different NOx prediction models. Both of the unsteady flamelet model and the Leed's NOx model underestimated the NOx emissions significantly at all power setting conditions. The CRN model predictions, however, show good agreement with the ICAO databank at high power setting conditions, but a slight discrepancy exists at the idle power point. This could be related to the reactive flow field is not captured accurately by the laminar flamelet model in idle condition. The 
Damköhler numbers at the low power setting condition is quite small compared to the value at high power setting conditions. Sanders et al. ${ }^{[45]}$ compared the flow field with different Damköhler numbers and concluded that the flamelet approach is appropriate for high Damköhler values. In gas turbine combustors, at takeoff condition, the Damköhler number could reach 150 while at idle condition the value is only $6.5^{[46]}$. Thus, based on the consideration of the computation accuracy and the fact that steam is primarily applied for airplane takeoff, the takeoff condition was chosen to investigate the effect of steam addition on NOx emission.

\subsection{Steam addition on NOx emissions}

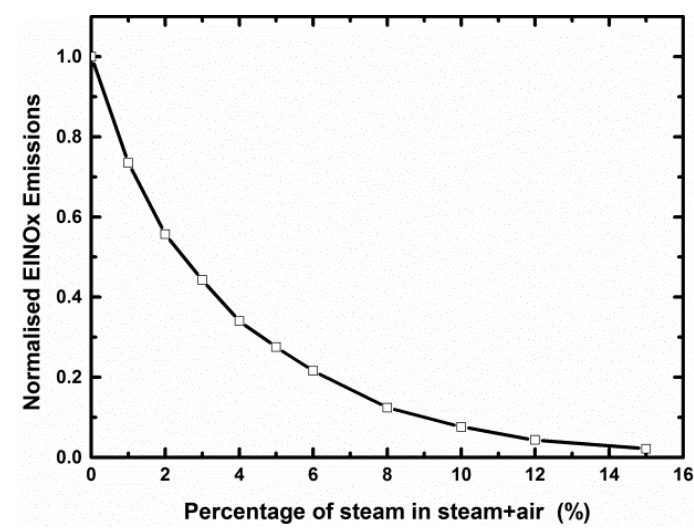

Figure. 9 Influence of steam dilution on the overall NOx emission

Figure.9 displays the NOx emissions against the steam mass fraction. The calculated NOx emissions are normalised by the ICAO data. When the steam content is not very high (less than 6\%), the NOx emission reduces quickly when the steam mass fraction increases. However, when it is high enough (larger than $8 \%$ ), the effect of steam addition is not obvious as the NOx emissions are nearly kept the same even the steam mass fraction increases. When the steam mass fraction reaches as high as $15 \%$, most of the 
NOx emission (94\%) could be eliminated, which shows the steam plays an important role in NOx decrease at takeoff condition.

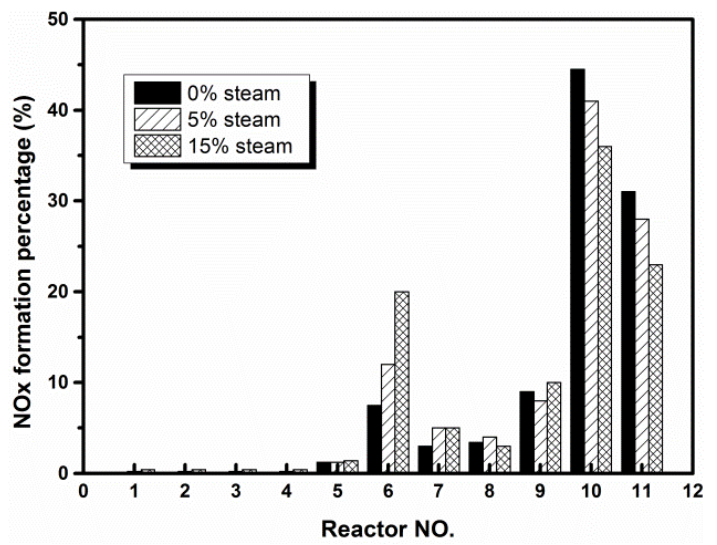

Figure.2 NOx formation percentage distribution for each reactor at take-off condition

The percentage of the NOx production (NOx production percentage $=$ $\left.\mathrm{m}_{\text {NOx formation in any reactor }} / m_{\text {total NOx formation }}\right)$ in each reactor is plotted in Figure.10. For any steam mass fraction, the largest NOx formation region occurs in both the core flame zone (PSR10) and the dilution zone (PFR11). As shown in Figure.5, a part of the dilution zone is located at the post flame zone, where the rate of NOx production is high. Therefore, the primary NOx reaction region occurs at both the main flame and the post flame zones. As the steam mass fraction increases, the amount of the NOx production in the primary zone (PSR6) decreases, whereas it increases in the secondary zone. This means the addition of steam would push the NOx production region downstream.

Table 4 shows the contributions of different combustion zones to the NOx emission at different steam additions. This table consists of two parts. In the first part, the division of different zones is based on the flow field characteristics. It is shown that most of the NOx is produced in the main flame. When the steam mass fraction increases, a relative higher amount of NOx is formed at the post flame zone. As illustrated above, steam 
addition would provide larger radical pools, especially for $\mathrm{OH}$ radicals, which leads more NOx emissions in the post flame zone. At the second part, the division is directly from the combustor configuration. It could be seen that most of the NOx production occurs in the secondary zone at both dry and wet conditions. The primary contribution of NOx production is in the high temperature flame region. As illustrated in the CFD analysis section, with the steam addition, the size of high temperature zone is reduced and subsequently, the corresponding reaction rates are lower. Therefore, the steam addition has a strong effect on the NOx emission reduction at the first part of main flame region which is located in the primary zone. Primary zone is the most important region where steam could effectively restrain NOx emissions.

Table 4. NOx formation percentage distribution in different reaction zones

\begin{tabular}{ccccccc}
\hline Steam & \multicolumn{5}{c}{ Different zones } \\
mass & Corner recir & Main recir & Main flame & Premixed & Post flame & Near-wall \\
fraction & (PSR 1,2,5) & (PSR 3,6,7) & (PSR 6,10) & (PSR 1-4) & (PFR 11) & (PSR 1,5,8) \\
$0 \%$ & $2.2 \%$ & $5.8 \%$ & $56 \%$ & $2 \%$ & $23 \%$ & $4.8 \%$ \\
$5 \%$ & $1.6 \%$ & $5.4 \%$ & $53 \%$ & $0.8 \%$ & $28 \%$ & $5.4 \%$ \\
$15 \%$ & $1.4 \%$ & $3.2 \%$ & $52 \%$ & $0.4 \%$ & $31 \%$ & $4.7 \%$ \\
\cline { 2 - 6 } & \multicolumn{2}{c}{ Primary zone } & Secondary zone & Diluent zone \\
$5 \%$ & $28 \%$ & \multicolumn{2}{c}{$49 \%$} & $23 \%$ \\
$15 \%$ & $19 \%$ & $53 \%$ & $28 \%$ \\
\hline
\end{tabular}

\section{Conclusion}

This paper deals with the analysis of the flow field and NOx emissions with steam addition for an annular turbofan combustor. The study aims at evaluating the capability of steam injection technology for NOx reduction in aircraft engine application. The engine cycle is reconstructed and validated by open data to obtain the combustor operating conditions. CFD models are validated. Different mechanisms of steam chemical effect are summarized and the effect of steam on the combustion process is addressed using an 
appropriate chemical mechanism. Based on the flow field, a CRN is built, and different NOx prediction models are employed and compared with ICAO databank.

At fuel rich condition, steam addition would lead the Jet-A flame temperature decrease. However, in fuel lean situation, there is a limit at which the chemical enhancement effect could counteract its thermo-physical inhibition effects. Smaller equivalence ratio results in a wider range for which steam could enhance combustion.

The CFD results show that the steam addition has a limited influence on the configuration of the flow field. Steam primarily affects the high temperature reactive region in the combustor. It reduces the size of high temperature zone and pushes the radical pool downstream. Compared with the other two NOx prediction models, it is shown that the CRN model could obtain more accurate results. In the annular combustor, larger amount of NOx is produced at both the primary and the secondary zones without steam injection while at wet conditions, the NOx formed in the dilution zone could exceed the NOx produced in the primary zone. Thus, the NOx formation region moves downstream when steam is injected. For both dry and wet operations, the primary NOx production region is in the main flame and the post flame zones. This is mostly due to the high temperature of these two zones, in which the Zeldovich pathway is dominant for NOx formation. Through significantly reducing the size of the high temperature region, NOx formation is effectively inhibited by steam addition. The results in this study are promising enough to warrant a deeper look at the possibilities this technology might offer. 
Acknowledgements: China Scholarship Council is gratefully acknowledged for the grant to R. Xue.

\section{Funding}

This paper is supported by the National Science and Foundation of China. This work has been supported by the National Natural Science Foundation of China (Grant No. $51576166)$

\section{References}

[1] Marchionna N. R., Diehl L. A., Trout A. M., "The effect of water injection on nitric oxide emissions of a gas turbine combustor burning ASTM Jet-A fuel", NASA Technical Memorandum X-2958, 1973.

[2] Dryer F. L., "Water addition to practical combustion systems-concepts and applications", 16th Symposium on Combustion/The Combustion Institute, 1976.

[3] Miyauchi Y., Mori Y., Yamaguchi T., "Effect of steam addition on NO formation", 18th Symposium on Combustion/The Combustion Institute, 1981.

[4] Touchton G. L., "Influence of gas turbine combustor design and operating parameters on effectiveness of NOx suppression by injected steam or Water", Journal of Engineering for Gas Turbines and Power., Vol.107, 1994, pp.706-13.

[5] Krüger O., Terhaar S., Paschereit C. O., Duwig C., "Large eddy simulations of hydrogen oxidation at ultra-wet conditions in a model gas turbine combustor applying detailed chemistry", Journal of Engineering for Gas Turbines and Power., Vol.135, 2013, pp.021501-1-10.

[6] Kuehl D., "Effects of water on burning velocity of hydrogen-air flames", ARSJ., Vol.3, 1962, pp.1724-1726.

[7] Levy A., "Effects of water on hydrogen flames", AIAA Journal, Vol.1, 1963, pp.1239-1244. 
[8] Koroll G. W., Mulpuru S. R., "The effect of dilution with steam on the burning velocity and structure of premixed hydrogen flames", 21st Symposium on Combustion/The Combustion Institute, 1988.

[9] Liu D., MacFarlane R., "Laminar burning velocities of hydrogen-air and hydrogen-air-steam flames", Combustion and Flame, Vol. 49, 1983, pp.59-71.

[10] Babkin V., V'yun A., "Effect of water vapor on the normal burning velocity of a methane-air mixture at high pressures", Combust Explo Shock, Vol. 7, 1971, pp.339341.

[11]Gurentsov E. V., Divakov O. G., Eremin A. V., "Ignition of multicomponent hydrocarbon/air mixtures behind shock waves", High Temp, Vol.40, 2002, pp.37986.

[12] Hwang D. J., Choi J. W., Park J. , Keel S. I. , Ch C. B., "Numerical study on flame structure and $\mathrm{NO}$ formation in $\mathrm{CH}_{4}-\mathrm{O}_{2}-\mathrm{N}_{2}$ counterflow diffusion flame diluted with H2O", International Journal of Energy Res, Vol.28, 2004, pp.1255-1267.

[13] Mazas A., Fiorina B., Lacoste D., Schuller T., "Effects of water vapor addition on the laminar burning velocity of oxygen-enriched methane flames", Combustion and Flame, Vol.158, 2011, pp.2428-2440.

[14] Göke S., Füri M., Bourque G., Bobusch B., Göckeler K., Krüger O., "Influence of steam dilution on the combustion of natural gas and hydrogen in premixed and rich-quench-leancombustors", Fuel Process and Technology, Vol.107, 2012, pp.1422.

[15] Daggett D. L., "Water misting and injection of commercial aircraft engines to reduce airport NOx", NASA Contractor Report NO.212957Cleveland, 2004..

[16] Balepin V., Ossello C., Snyder C., "NOx emission reduction through water injection in Commercial Jets", NASA Contractor Report NO.211978, 2002.

[17] Benini E., Pandolfo S., Zoppellari S., "Reduction of NO emissions in a turbojet combustor by direct water/steam injection: Numerical and experimental assessment", Applied Thermal Engineering, Vol.29, 2009, pp.3506-3510. 
[18] Riesmeier E., Honnet S., Peters N., "Flamelet modeling of pollutant formation in a gas turbine combustion chamber using detailed chemistry for a kerosene model fuel", Journal of Engineering for Gas Turbine and Power, Vol. 126, 2004, pp.899-905.

[19] Pitsch H., Chen M., Peters N., "Unsteady flamelet modeling of turbulent hydrogen-air diffusion flames", 27th Symposium on Combustion/The Combustion Institute, 1998.

[20] Jiang L. Y., Campbell I., "A critical evaluation of NOx modeling in a model combustor", Journal of Engineering for Gas Turbine and Power, Vol.127, 2005, pp. 483-491.

[21]Gobbato P., Masi M., Toffolo A., Lazzaretto A., Tanzini G., "Calculation of the flow field and NOx emissions of a gas turbine combustor by a coarse computational fluid dynamics model", Energy Vol.45, 2012, pp.445-455.

[22]Falcitelli M., Pasini S., Rossi N., Tognotti L., “CFD + reactor network analysis: an integrated methodology for the modeling and optimisation of industrial systems for energy saving and pollution reduction", Appllying Thermal Engineering, Vol.22, 2002, pp.971-979

[23] Mancini M., Schwöppe P., Weber R., Orsino S., "On mathematical modeling of flameless combustion", Combustion and Flame, Vol.150,2007, pp.54-59.

[24]Park J., Nguyen T. H., Joung D., Huh K. Y., Lee M. C., "Prediction of NO x and CO emissions from an industrial Lean-Premixed gas turbine combustor using a chemical reactor network model", Energy \& Fuels, Vol.27, 2013, pp.1643-1651.

[25] Falcitelli M., Pasini S., Rossi N., Tognotti L., "CFD reactor network analysis: an integrated methodology for the modeling and optimization of industrial systems for energy saving and pollution reduction", Appllied Thermal Engineering, Vol.22, 2002, pp.971-979.

[26] Kunz O., Noll B., Lueckerath R., "Computational Combustion Simulation for an Aircraft Model Combustor", AIAA paper, 2001. 
[27] Cuoci A., Frassoldati A., Faravelli T., "CFD Simulation of a Turbulent Oxy-Fuel Flame" Processes and Technologies for Sustainable Energy, 2010.

[28] Warnatz J., Mass U., Dibble R. W., Combustion, 1996, pp. 219-221.

[29] Crowe C., Sommerfield M., Tsuji Y., "Multiphase flows with droplets and particles", CRC Press, 1998.

[30] Andreini A., Facchini B., "Gas turbines design and off-design performance analysis with emissions evaluation", Journal of Engineering for Gas Turbine and Power, Vol.126, 2004, pp.83-91.

[31] Pellett G. L., Wilson L. C., Northam G. B., Guerra R., "Effects of $\mathrm{H}_{2} \mathrm{O}, \mathrm{CO}_{2}$, and $\mathrm{N}_{2}$ air contaminants on critical airside strain rates for extinction of hydrogen-air counterflow diffusion flames", NASA Contractor Report NO. 19900034881, 1989.

[32] Strelkova M. I., Kirilov I. A., Potapkin B. V., Safonov A. A., Sukhanov L. P.,Umanskiy S. Y., "Detailed and reduced mechanism of jet A combustion at high temperatures", Combustion science and technolology, Vol.180, 2008, pp.17881802.

[33]Luche J., Reuillon M., Boettner J. C., Cathonnet M., "Reduction of large detailed kinetic mechanism: Application to kerosene/air combustion", Combustion science and technology, Vol.176, 2004, pp.1935-1963.

[34]Sturgess G. J., "Assessment of an abbreviated Jet-A/JP-5/JP-8 reaction mechanism for modeling gas turbine engine gaseous emissions" AIAA Report No 97-2709, 1997.

[35]Sturgess G. J., Shouse D. T., "A hybrid model for calculating lean blow-outs in practical combustors", AIAA Report No 96-3125, 1996.

[36]Gordon S., McBride B. J., "Computer program for calculation of complex chemical equilibrium and applications: Part I.", NASA Report No 1311, 1994.

[37]Dally B. B., Masri A. R., Barlow R. S., Fiechtner G. J., "Instantaneous and mean compositional structure of bluff-body stabilized nonpremixed flames", Combustion and Flame, Vol.114, 1998, pp.119-148. 
[38]Nikolaou Z. M., Chen J-Y., Swaminathan N., "A 5-step reduced mechanism for combustion of $\mathrm{CO} / \mathrm{H}_{2} / \mathrm{H}_{2} \mathrm{O} / \mathrm{CH}_{4} / \mathrm{CO}_{2}$ mixtures with low hydrogen/methane and high H2O content", Combustion and Flame, Vol.160, 2013, pp.56-75.

[39]Gunston B., Jane's Aero-Engines, 29th Edition, 1996.

[40] Palmer J. R., "The TURBOMATCH scheme for gas turbine", Cranfield University: Unpublished TURBOMATCH manual, 2011.

[41]Vassilios A. P., "Gas turbine performance simulation", Cranfield University: Unpublished lecture notes, 2011.

[42] "International Civil Aviation Organization aircraft engine emissions databank", International Civil Aviation Organization Doc. 9646-AN/943, 1995.

[43]Bailey A. G., Balachandran W., Williams T. J., "The rosin-rammler size distribution for liquid droplet ensembles", Journal of aerosol science, Vol.14, 1983; pp.39-46.

[44]Lefebvre A. H., “Gas turbine combustion”, Philadelphia: Taylor \& Francis, 1999. [45]Sanders J. P. H., Chen J. Y., Gökalp I., "Flamelet-based modeling of NO formation in turbulent hydrogen jet diffusion flames", Combustion and flame, Vol. 111, 1997, pp.1-15.

[46]Zedda M., "Gas turbine combustor short course", Cranfield University: Unpublished lecture notes, 2013. 


\section{Figure Captions List}

At the sentence beginning write Figure (not Fig.)

Fig. 1:Adiabatic flame temperature of Jet-A at takeoff condition for different steam levels

Fig. 2: Mean values of a) mixture fraction and $b$ ) axial velocity profiles in $r$ direction at $x / D=10$ and 20

Fig. 3: Mean values of temperature and mixture fraction profiles in $x$ direction at centreline

Fig. 4: Single-cup sector of the combustor chamber

Fig. 5: Contours of the a) Total temperature and b) $\mathrm{OH}$ radical distribution in the immediate plane of the combustor at takeoff condition for the dry $(\mathrm{W}=0 \%)$ and wet cases $(\mathrm{W}=15 \%) \quad\left(\mathrm{T}_{\mathrm{air}}\right.$ or $\mathrm{T}_{\text {air/steam }}=725.54 \mathrm{~K}$, Jet- $\mathrm{A}$ droplet $=298.15 \mathrm{~K})$

Fig. 6: Radial distribution of axial velocity at a) the primary jet and b) the secondary jet cross sections

Fig. 7: A 14-element CRN used to calculate the NOx emission of this generic combustor model

Fig. 8: Comparison of EINOx prediction with test data at different power setting conditions

Fig. 9: Influence of steam dilution on the overall NOx emission

Fig. 10: NOx formation percentage distribution for each reactor at take-off condition 
International Journal of Turbo \& Jet-Engines. Volume 33, Issue 4, Pages 381-393

\section{Table Caption List}

Table 1 Comparison of computed cycle data (by TurboMatch) and published $\operatorname{data}^{[40]}$

Table $2 \quad$ Mass fraction for different air inlets at take-off condition

Table 3 Comparison of the combustor outlet temperatures calculated by CFD and Turbomath

Table $4 \quad$ NOx formation percentage distribution in different reaction zones 
Figures

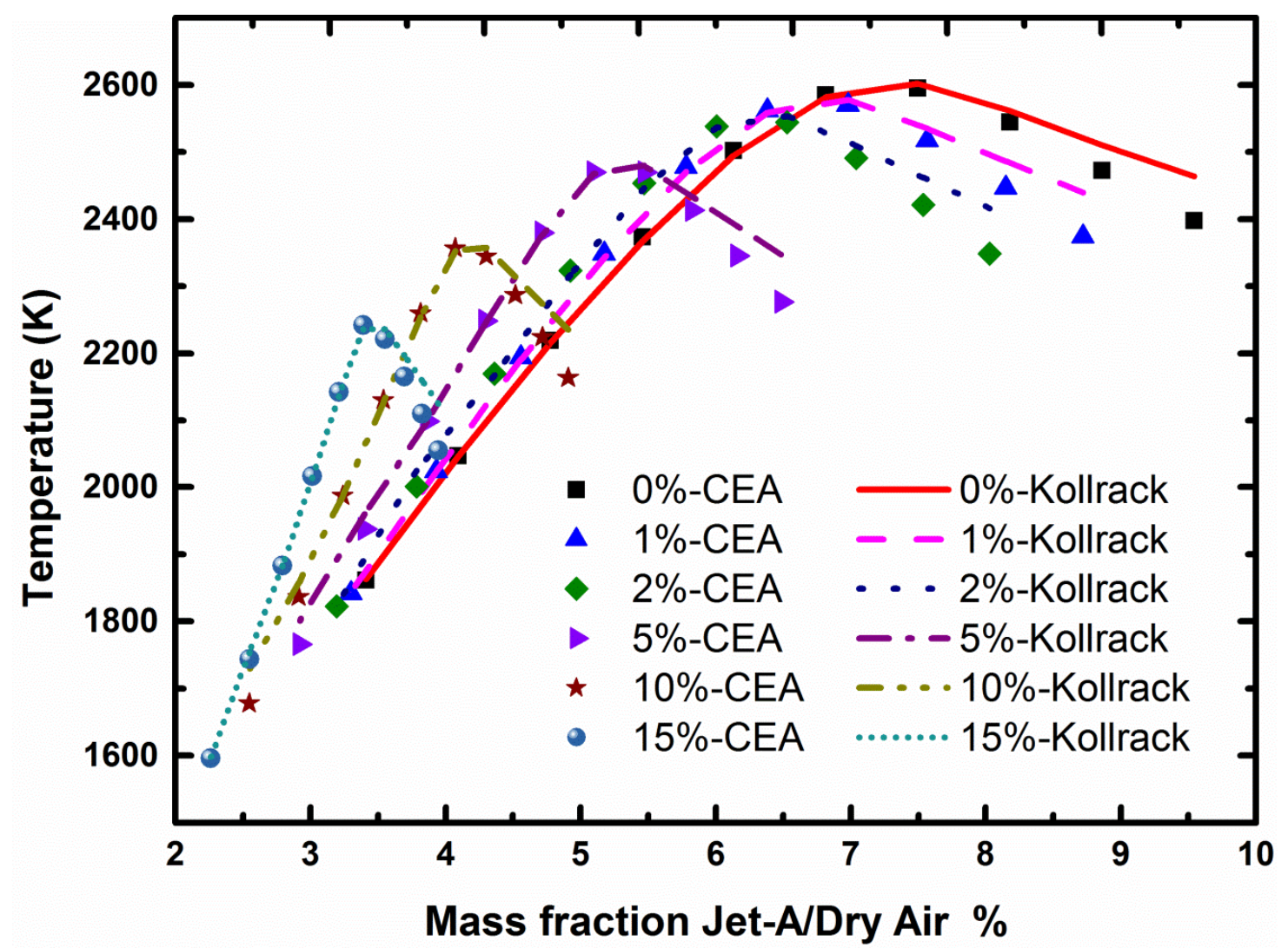

Fig.3.Adiabatic flame temperature of Jet-A at takeoff condition for different steam levels 

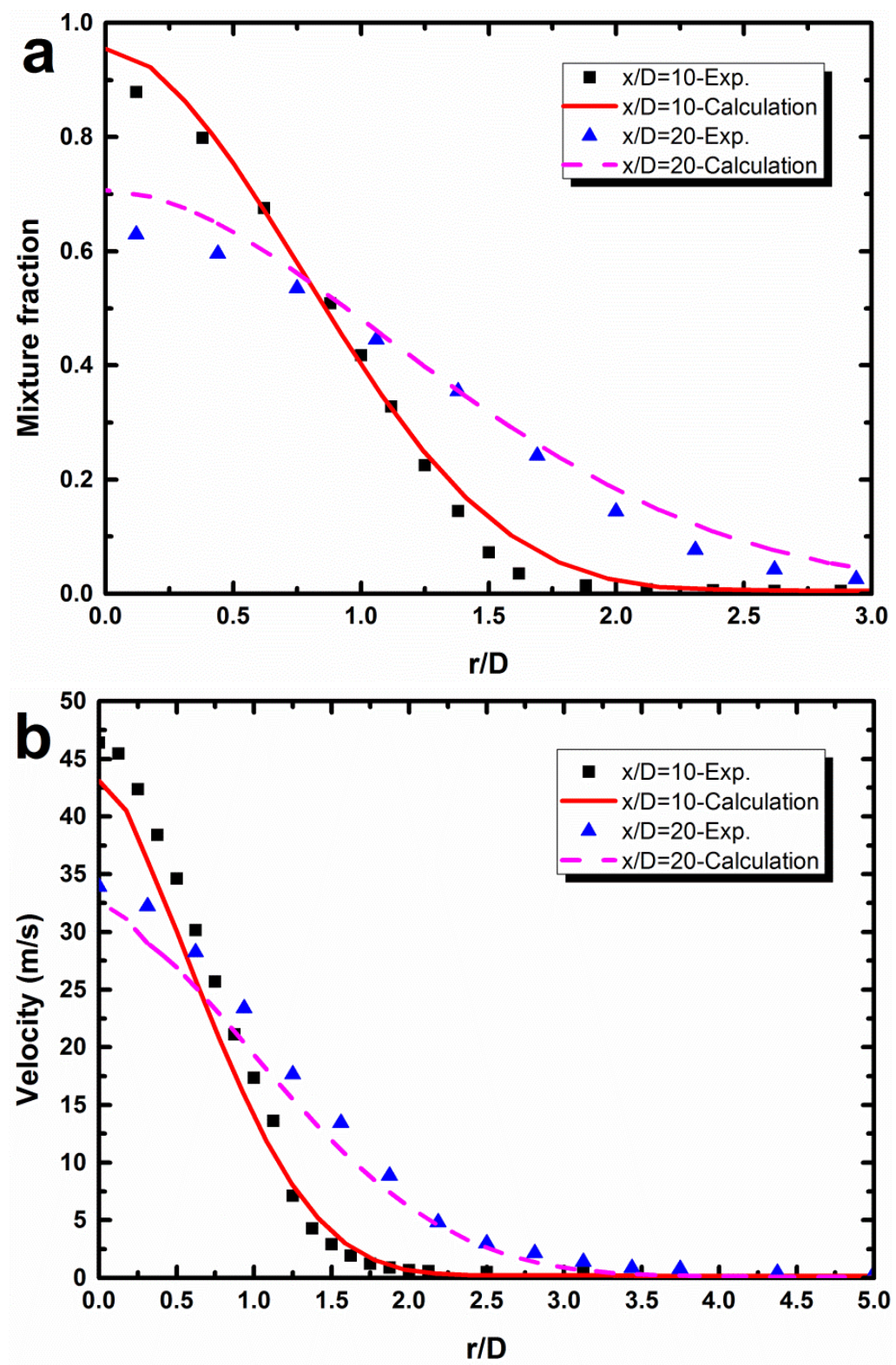

Fig. 2. Mean values of a) axial velocity and b) mixture fraction profiles in $r$ direction at $x / D=10$ and 20 
International Journal of Turbo \& Jet-Engines. Volume 33, Issue 4, Pages 381-393

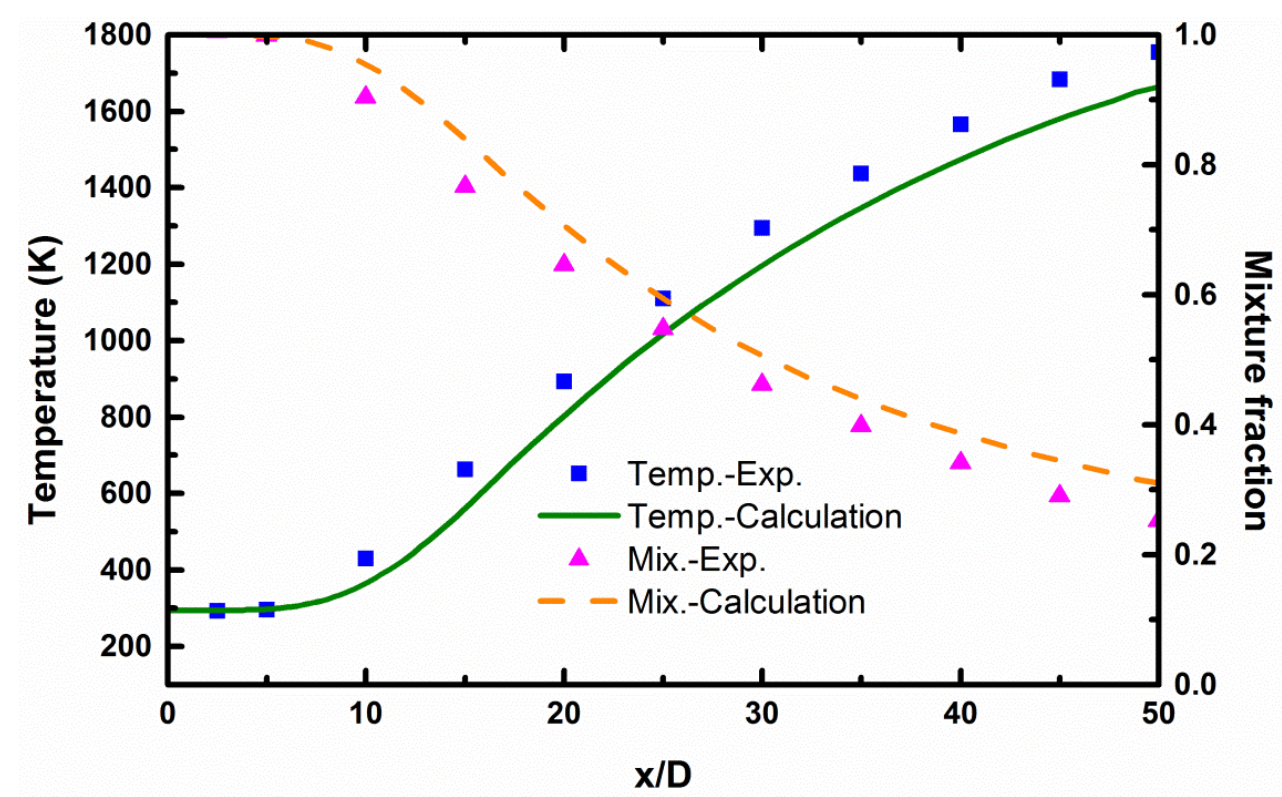

Fig. 3. Mean values of temperature and mixture fraction profiles in $\mathrm{x}$ direction at centreline 
International Journal of Turbo \& Jet-Engines. Volume 33, Issue 4, Pages 381-393

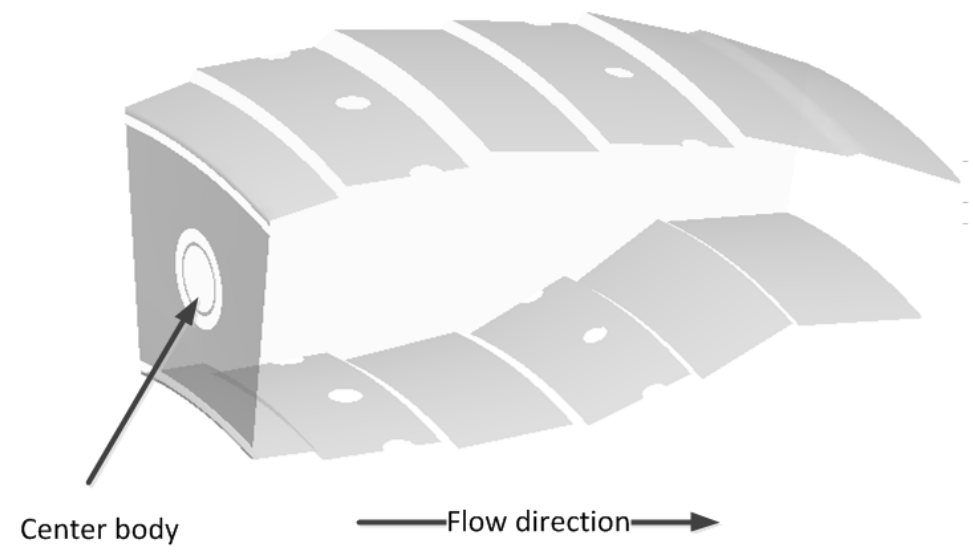

Fig. 4.Computational domain-Single-cup sector of the combustor chamber 


\section{a}
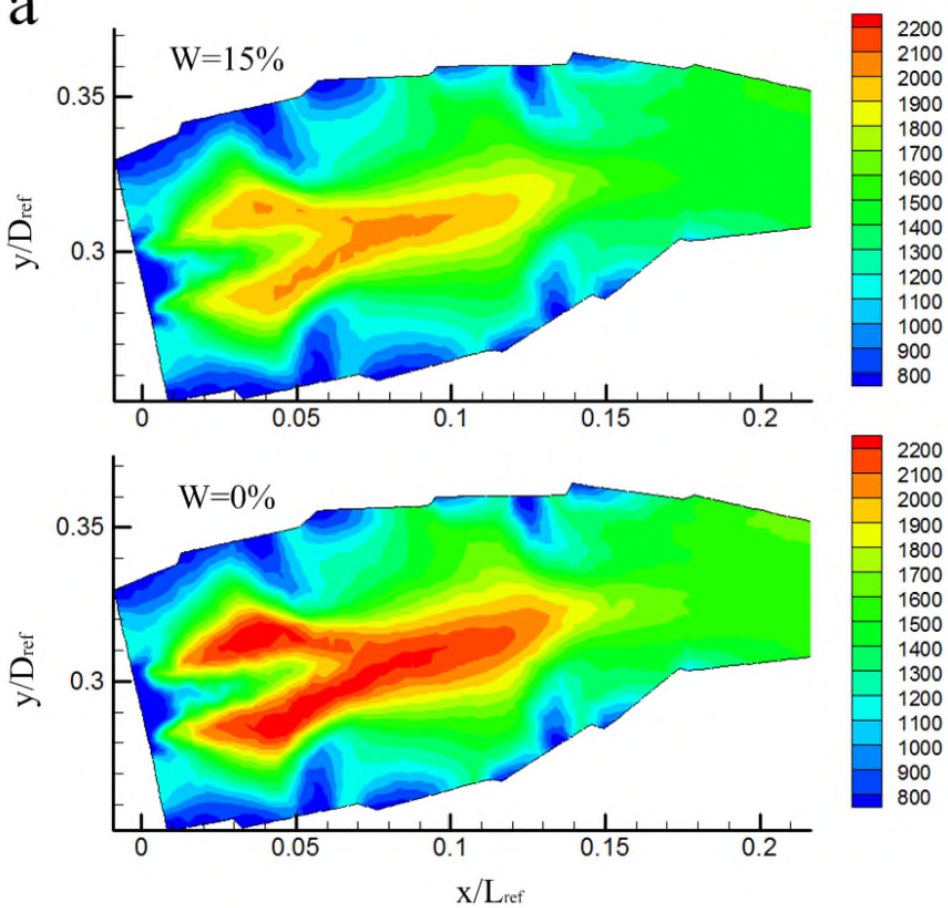

b
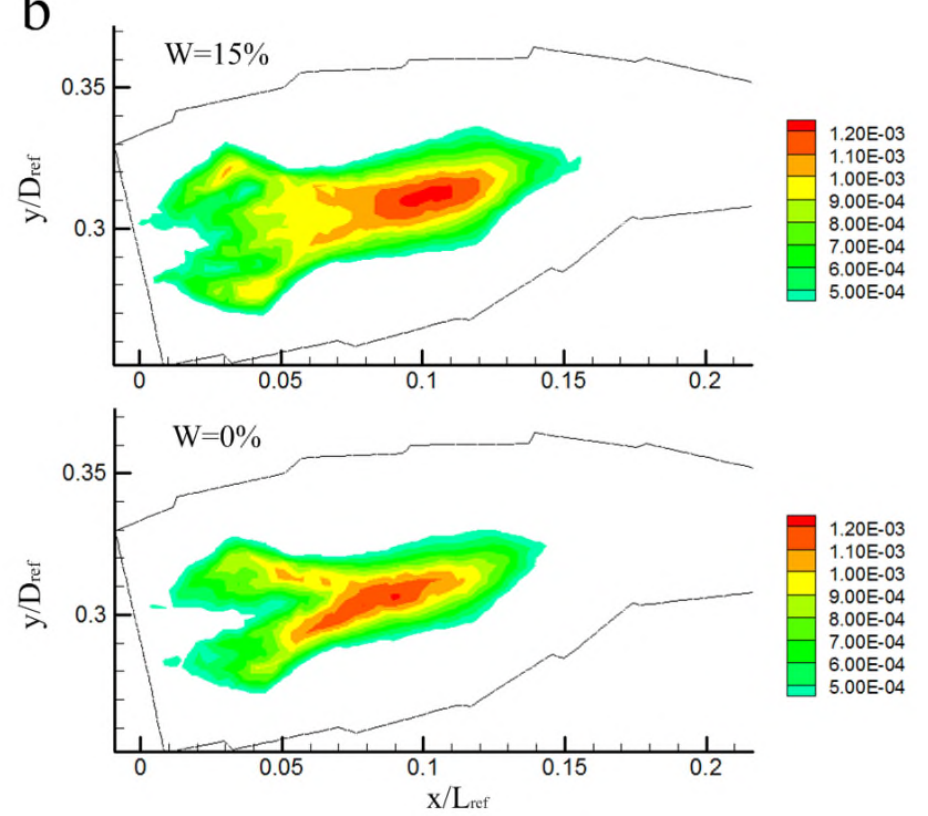

Fig. 5. Contours of the a) Total temperature and b) $\mathrm{OH}$ radical distribution in the immediate plane of the combustor at takeoff conditionfor the dry and wet $\operatorname{cases}\left(\mathrm{T}_{\text {air }}\right.$ or $\mathrm{T}_{\text {air } / \text { steam }}=725.54 \mathrm{~K}$, Jet-A droplet=298.15K) 

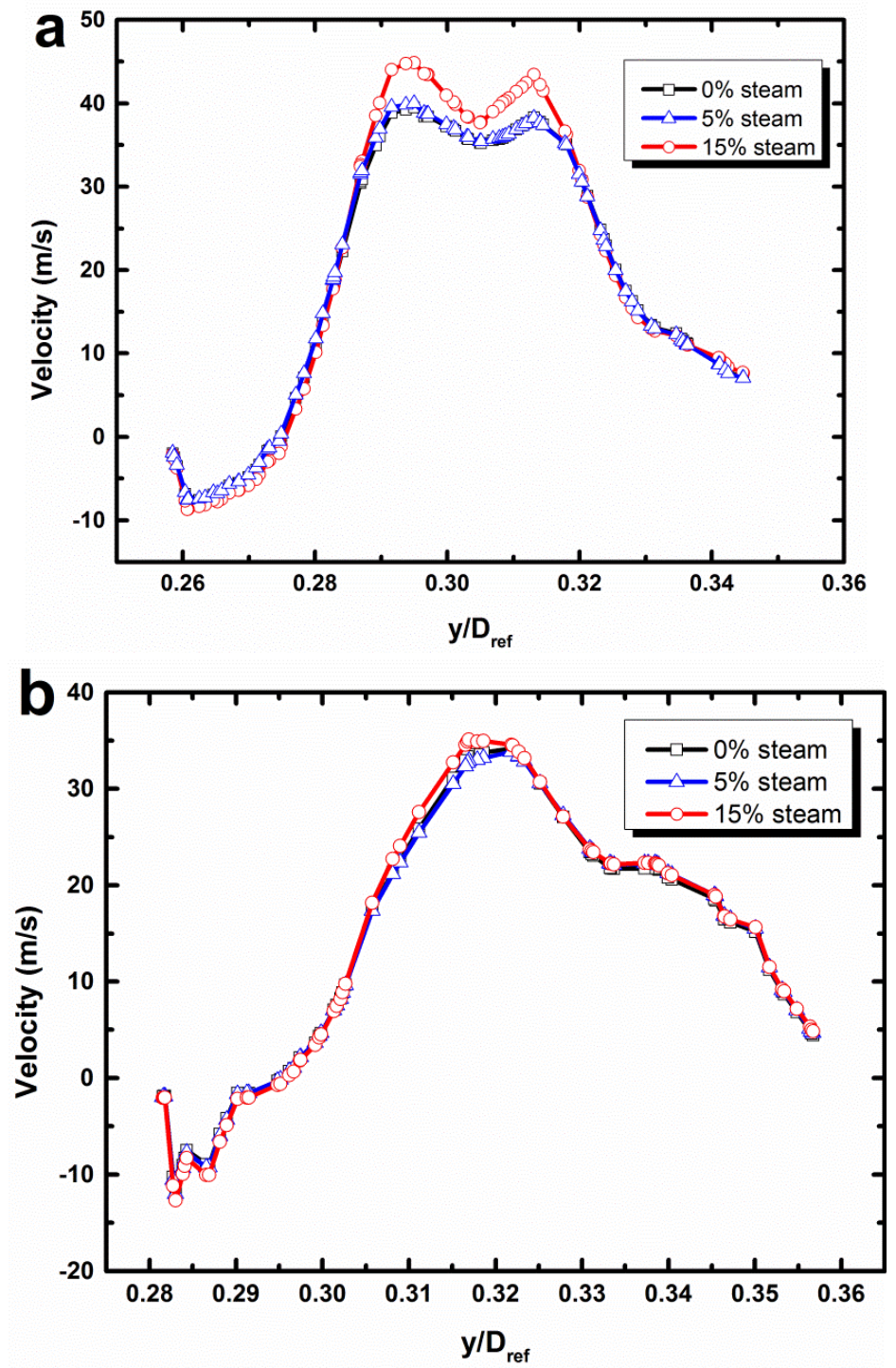

Fig. 6.Radial distribution of axial velocity at a) the primary jet and b) the secondary jet cross sections 
International Journal of Turbo \& Jet-Engines. Volume 33, Issue 4, Pages 381-393

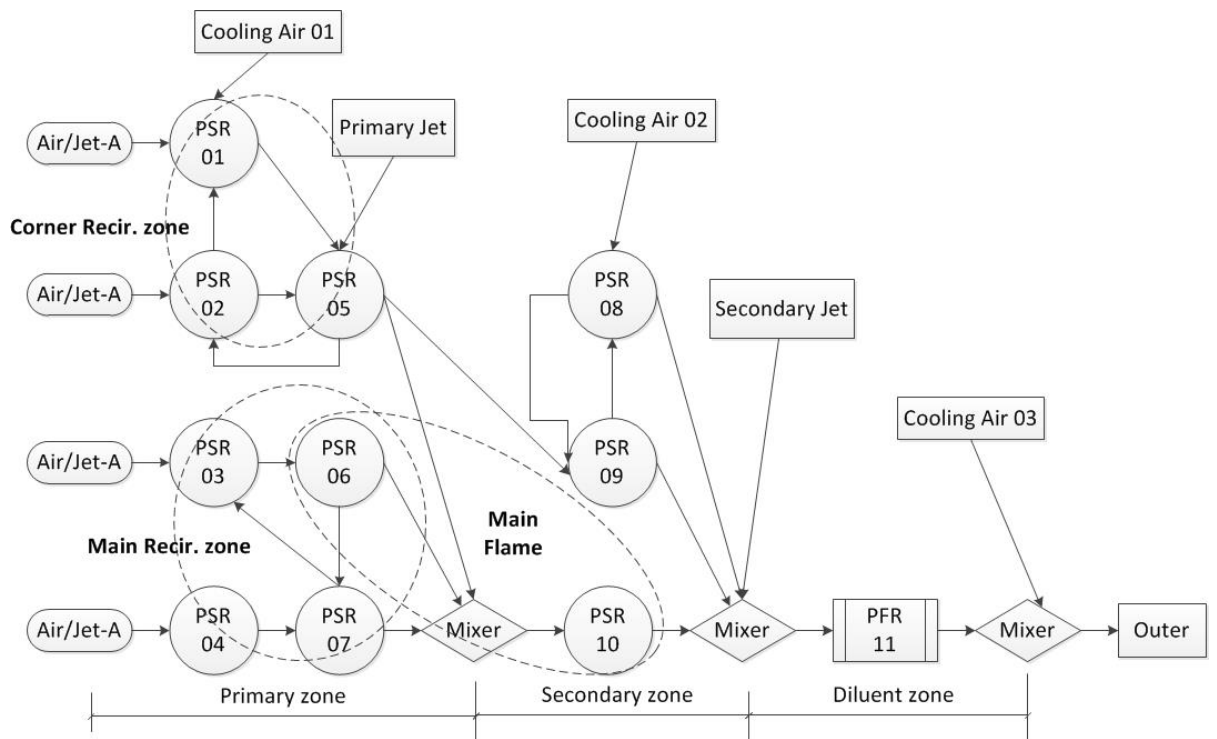

Fig. 7.A 14-element CRN used to calculate the NOx emission of this general combustor model 
International Journal of Turbo \& Jet-Engines. Volume 33, Issue 4, Pages 381-393

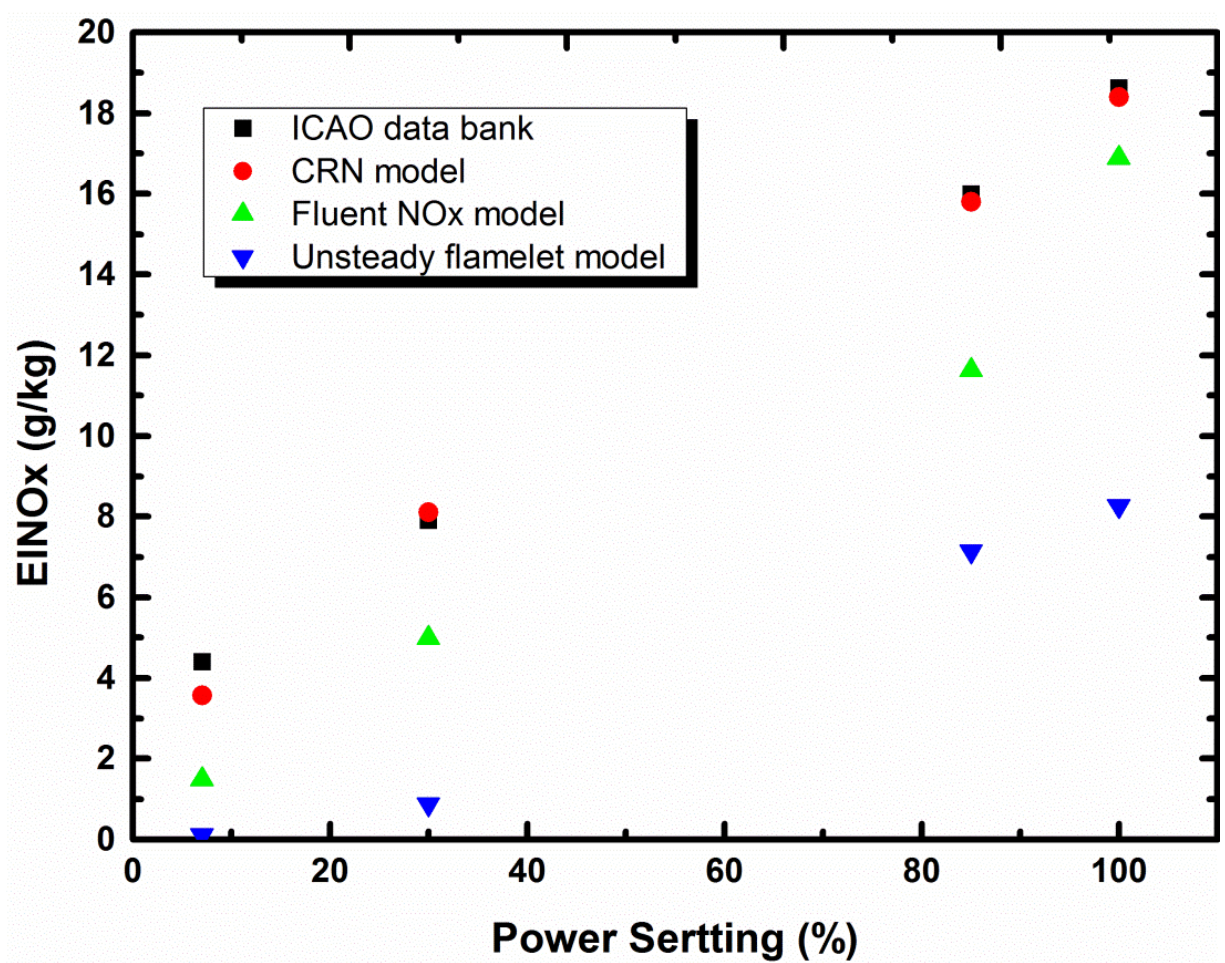

Fig. 8.Comparison of EINOxprediction with test data at different power setting conditions 
International Journal of Turbo \& Jet-Engines. Volume 33, Issue 4, Pages 381-393

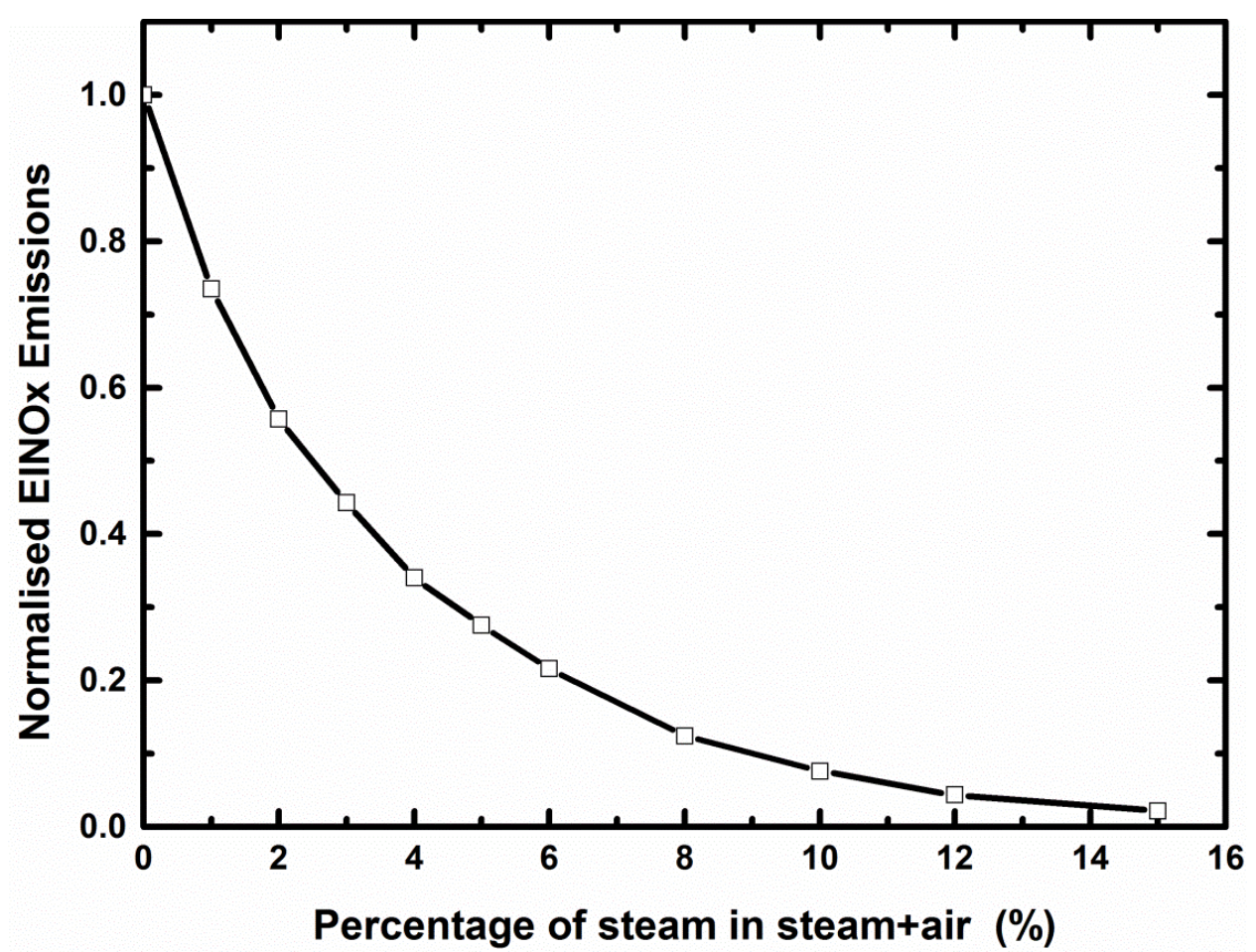

Fig. 9.Influence of steam diluent on the overall NOx emission at the combustor exit 
International Journal of Turbo \& Jet-Engines. Volume 33, Issue 4, Pages 381-393

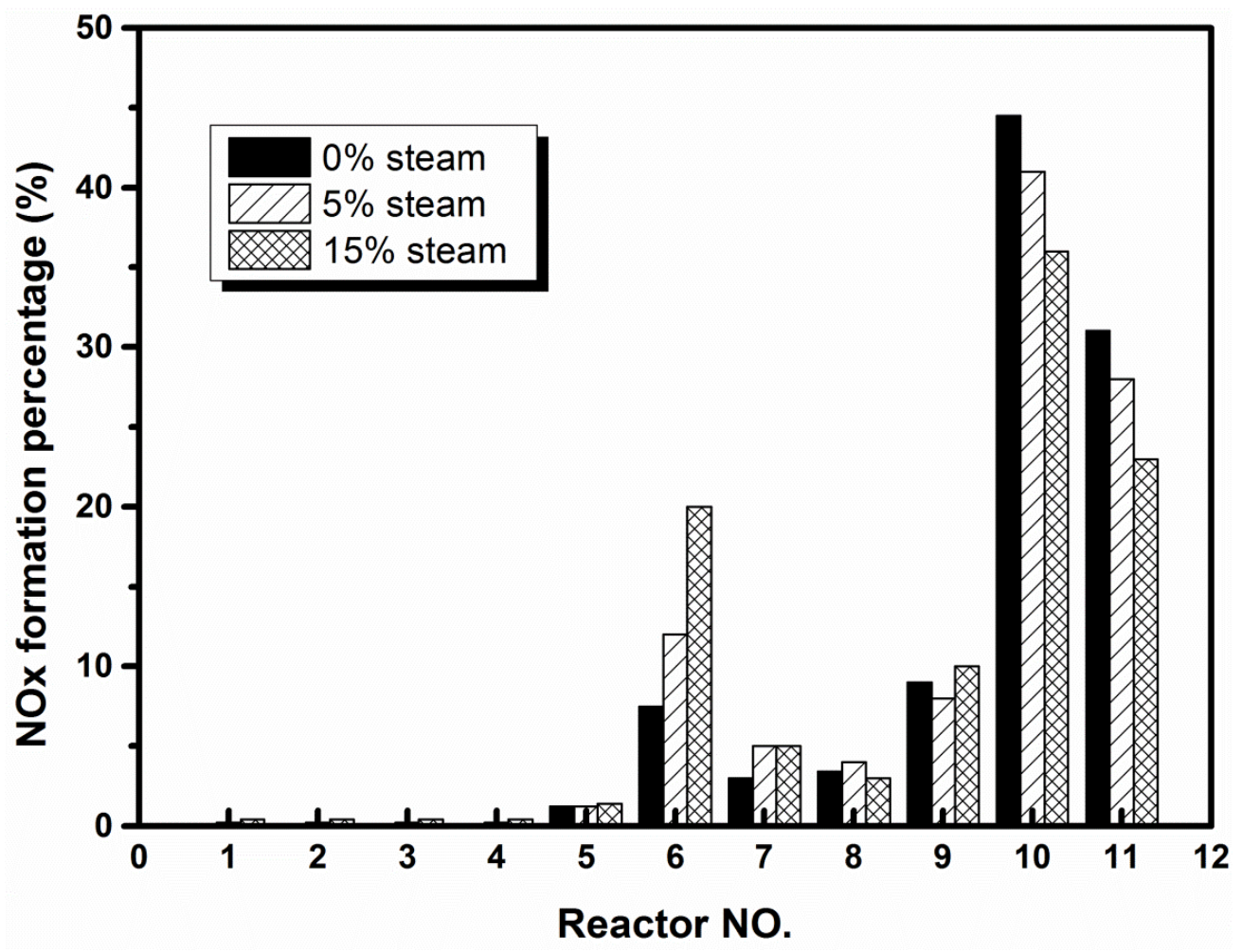

Fig.10.NOx formation percentage for each reactor at take-off condition 
International Journal of Turbo \& Jet-Engines. Volume 33, Issue 4, Pages 381-393

\section{Tables}

Table 1 Comparison of computed cycle data (by TurboMatch) and published data ${ }^{[40]}$

\begin{tabular}{|c|c|c|c|c|c|c|}
\hline \multicolumn{2}{|c|}{ Engine parameters } & Simulation & \multicolumn{2}{|c|}{ ICAO data bank } & \multicolumn{2}{|c|}{ Deviation } \\
\hline \multicolumn{7}{|c|}{ DP (Takeoff) } \\
\hline \multirow{2}{*}{\multicolumn{2}{|c|}{$\begin{array}{l}\text { Thrust (kN) } \\
\text { SFC (mg/Ns) }\end{array}$}} & 43.06 & \multicolumn{2}{|c|}{42.23} & \multicolumn{2}{|r|}{$1.9 \%$} \\
\hline & & 10.85 & \multicolumn{2}{|c|}{9.35} & \multicolumn{2}{|r|}{$16.0 \%$} \\
\hline & Flow(kg/s) & ICAO data bank $(\mathrm{kg} / \mathrm{s})$ & Deviation & $\mathrm{P}_{3}(\mathrm{~atm})$ & $\mathrm{T}_{3}(\mathrm{~K})$ & Air flow rate $(\mathrm{kg} / \mathrm{s})$ \\
\hline Takeoff & 0.4683 & 0.466 & $0.49 \%$ & 20.0 & 725.5 & 19.6 \\
\hline Climbout & 0.3745 & 0.388 & $-3.4 \%$ & 17.4 & 691.2 & 17.7 \\
\hline Approach & 0.1207 & 0.138 & $-12.5 \%$ & 8.4 & 550.6 & 9.8 \\
\hline Idle & 0.0544 & 0.055 & $-1.1 \%$ & 4.3 & 469.2 & 5.0 \\
\hline
\end{tabular}


International Journal of Turbo \& Jet-Engines. Volume 33, Issue 4, Pages 381-393

Table.2 Mass fraction for different air inlets at take-off condition

\begin{tabular}{llc}
\hline & Feature & Mass flow (\%) \\
\hline Baseplate & Internal swirler & 9.14 \\
& External swirler & 18.5 \\
& Cooling ring & 2.8 \\
& Cooling ring & 3.82 \\
Outer & Cooling ring & 4.97 \\
liner & Dilution port & 8.89 \\
& Cooling ring & 4.76 \\
& Cooling ring & 5.41 \\
& Dilution port & 7.24 \\
Inner & Cooling ring & 5.01 \\
liner & Cooling ring & 3.55 \\
& Dilution port & 8.98 \\
& Cooling ring & 3.52 \\
& Cooling ring & 3.41 \\
& Dilution port & 5.72 \\
& Cooling ring & 3.50 \\
& Cooling ring & 0.78 \\
\hline
\end{tabular}


International Journal of Turbo \& Jet-Engines. Volume 33, Issue 4, Pages 381-393

Table.3 Comparison of the combustor outlet temperatures calculated by CFD and Turbomath

\begin{tabular}{cccc}
\hline \multicolumn{4}{c}{ Combustor outlet temperature } \\
\hline Power & CFD outlet mass-weight & Turbomatch turbine inlet & Difference \\
setting & average temperature(K) & temperature (K) & \\
Takeoff & 1511.151 & 1520 & $-0.58 \%$ \\
Climbout & 1399.455 & 1408 & $-0.607 \%$ \\
Approach & 1010.531 & 1003.95 & $0.656 \%$ \\
Idle & 893.9099 & 881.97 & $1.35 \%$ \\
\hline
\end{tabular}


International Journal of Turbo \& Jet-Engines. Volume 33, Issue 4, Pages 381-393

Table 4. NOx formation percentage distribution in different reaction zones

\begin{tabular}{|c|c|c|c|c|c|c|}
\hline \multirow{2}{*}{$\begin{array}{l}\text { Steam } \\
\text { mass } \\
\text { fraction }\end{array}$} & \multicolumn{6}{|c|}{ Different zones } \\
\hline & $\begin{array}{l}\text { Corner recir } \\
\text { (PSR } 1,2,5)\end{array}$ & $\begin{array}{c}\text { Main recir } \\
\text { (PSR 3,6,7) }\end{array}$ & $\begin{array}{l}\text { Main flame } \\
\text { (PSR 6,10) }\end{array}$ & $\begin{array}{l}\text { Premixed } \\
\text { (PSR 1-4) }\end{array}$ & $\begin{array}{c}\text { Post flame } \\
\text { (PFR 11) }\end{array}$ & $\begin{array}{r}\text { Near-wall } \\
\text { (PSR 1,5,8) }\end{array}$ \\
\hline $0 \%$ & $2.2 \%$ & $5.8 \%$ & $56 \%$ & $2 \%$ & $23 \%$ & $4.8 \%$ \\
\hline $5 \%$ & $1.6 \%$ & $5.4 \%$ & $53 \%$ & $0.8 \%$ & $28 \%$ & $5.4 \%$ \\
\hline \multirow[t]{2}{*}{$15 \%$} & $1.4 \%$ & $3.2 \%$ & $52 \%$ & $0.4 \%$ & $31 \%$ & $4.7 \%$ \\
\hline & \multicolumn{2}{|c|}{ Primary zone } & \multicolumn{2}{|c|}{ Secondary zone } & \multicolumn{2}{|c|}{ Diluent zone } \\
\hline $0 \%$ & \multicolumn{2}{|c|}{$28 \%$} & \multicolumn{2}{|c|}{$49 \%$} & \multicolumn{2}{|c|}{$23 \%$} \\
\hline $5 \%$ & \multicolumn{2}{|c|}{$19 \%$} & \multicolumn{2}{|c|}{$53 \%$} & \multicolumn{2}{|c|}{$28 \%$} \\
\hline $15 \%$ & \multicolumn{2}{|c|}{$12.1 \%$} & \multicolumn{2}{|c|}{$56.9 \%$} & \multicolumn{2}{|c|}{$31 \%$} \\
\hline
\end{tabular}


2015-08-13

\title{
Effect of steam addition on the flow field and NOx emissions for Jet-A in an aircraft combustor
}

\author{
Xue, Rui
}

Freund Publishing House / De Gruyter

Rui Xue, Chunbo Hu, Theoklis Nikolaidis and Pericle Pilidis. Effect of steam addition on the flow field and NOx emissions for Jet-A in an aircraft combustor. International Journal of Turbo \& Jet-Engines. Volume 33, Issue 4, pp381-393

http://dx.doi.org/10.1515/tjj-2015-0041

Downloaded from Cranfield Library Services E-Repository 